\title{
Evaluation of time out-based discipline strategy to manage children's noncompliance with cystic fibrosis treatment
}

\author{
Catherine Bradford McClellan \\ West Virginia University
}

Follow this and additional works at: https://researchrepository.wvu.edu/etd

\section{Recommended Citation}

McClellan, Catherine Bradford, "Evaluation of time out-based discipline strategy to manage children's noncompliance with cystic fibrosis treatment" (2004). Graduate Theses, Dissertations, and Problem Reports. 2120.

https://researchrepository.wvu.edu/etd/2120

This Dissertation is protected by copyright and/or related rights. It has been brought to you by the The Research Repository @ WVU with permission from the rights-holder(s). You are free to use this Dissertation in any way that is permitted by the copyright and related rights legislation that applies to your use. For other uses you must obtain permission from the rights-holder(s) directly, unless additional rights are indicated by a Creative Commons license in the record and/ or on the work itself. This Dissertation has been accepted for inclusion in WVU Graduate Theses, Dissertations, and Problem Reports collection by an authorized administrator of The Research Repository @ WVU.

For more information, please contact researchrepository@mail.wvu.edu. 
Evaluation of Time Out Based Discipline Strategy to Manage Children's Noncompliance with Cystic Fibrosis Treatment

Catherine Bradford McClellan

Dissertation submitted to the Eberly College of Arts and Sciences

at

West Virginia University

in partial fulfillment of the requirements

for the degree of

Doctor of Philosophy

in

Child Clinical Psychology

Lindsey Cohen, Ph.D., Chair

Cindy Anderson, Ph.D.

Kevin Larkin, Ph.D.

Cheryl McNeil, Ph.D.

Kathryn Moffett, M.D.

Department of Psychology

Morgantown, West Virginia

2004

Keywords: Cystic Fibrosis, Parent Training 


\begin{abstract}
Evaluation of Time Out Based Discipline Strategy to Manage Children's Noncompliance with Cystic Fibrosis Treatment

Catherine Bradford McClellan
\end{abstract}

Cystic Fibrosis (CF) is a chronic, terminal illness that requires intensive, time-consuming, and sometimes painful treatment for optimal health and longevity. Given the complex and aversive nature of treatment, children with CF frequently develop avoidance behaviors resulting in noncompliance to parents' treatment requests. The purpose of this study was to use a singlesubject reversal design to compare children's compliance with parents' typical strategies to children's compliance when a time out based discipline strategy is in effect. Participants were two children who displayed noncompliant behavior to their parent's treatment requests. Outcome measures included parent and child behaviors as assessed by an observational coding scheme of videotaped treatment observations, and parent report of their child's treatment-related behavior problems. Preliminary support was found for the hypothesized increase in compliant child behavior during the intervention conditions for one participant. Additionally, parents demonstrated moderate changes in their behaviors during the intervention condition. Parents also reported fewer treatment-related behavior problems and desired less professional help for these problems upon completion of the study. Finally, parents reported preferring the time out based discipline strategy over their typical child management strategy. 
Acknowledgements

I would like to thank and acknowledge my committee chair and graduate school mentor Lindsey Cohen, Ph.D. This project would not have been possible without his guidance, support and commitment to his students. I would also like to thank my committee members, Cindy Anderson, Ph.D., Cheryl McNeil, Ph.D., Kevin Larkin, Ph.D., and Kathryn Moffett, M.D. for their excellent suggestions and recommendations. I owe a debt of gratitude to my exceptional research assistants, Stephanie Gipson, Erica Dennis, Dan Hardesty, and Kassidy Haslacker who devoted many long hours to assisting me with this project.

I would like to thank Kathryn Moffett and Linda Baer for allowing me to recruit families through the WVU Cystic Fibrosis clinic. The families who participated in this research should be commended for their willingness to provide such an intimate portrait of their lives in an effort to promote the health and welfare of other families impacted by Cystic Fibrosis.

Without the endless support of my husband, family, and friends I would never have had the courage to undertake such a large goal. Finally, I would like to recognize my father, Christopher McClellan, a champion of intellectual curiosity, and my mother, Sylla McClellan, a woman who possesses endless compassion and empathy for others. Without their model, I could not be who or where I am today. 


\section{Table of Contents}

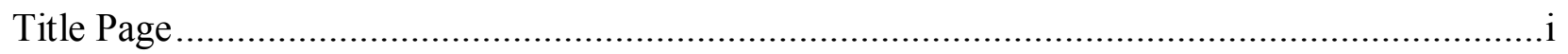

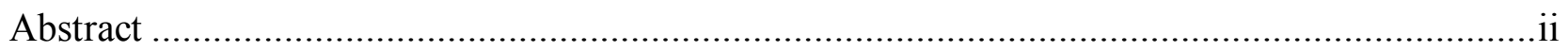

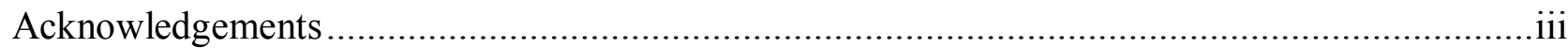

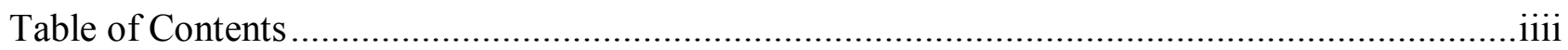

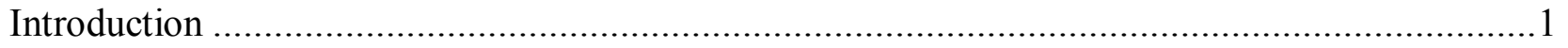

Overview of Cystic Fibrosis and Treatment of Cystic Fibrosis .................................... 1

Adherence to Cystic Fibrosis Treatment ...................................................................2

Noncompliance to Treatment Requests and Family Functioning ................................4

Interventions to Improve Adherence to Pediatric Medical Treatment ............................ 7

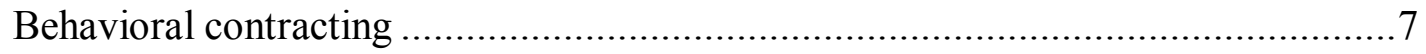

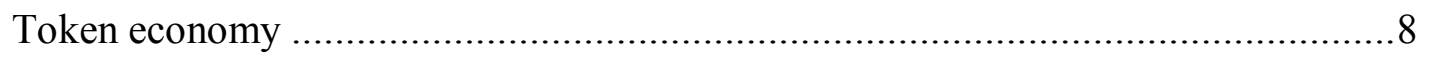

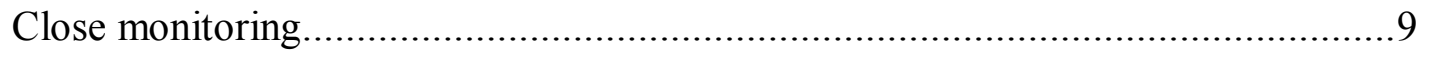

Multi-component behavioral management............................................... 10

Summary and Critique of the Literature ............................................................. 14

Time Out to Increase Adherence to Cystic Fibrosis Treatment ....................................16

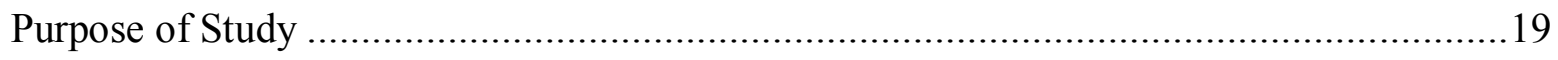

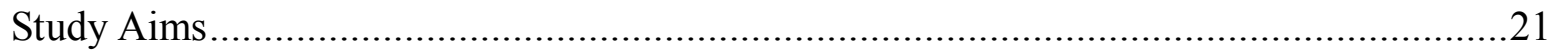

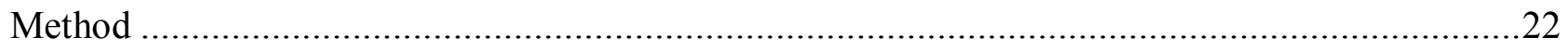

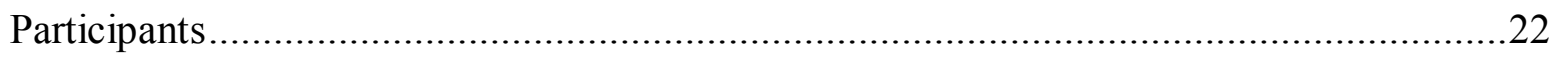

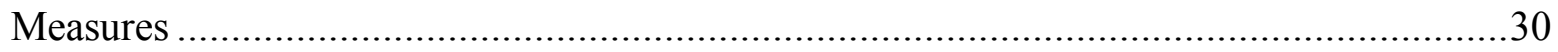

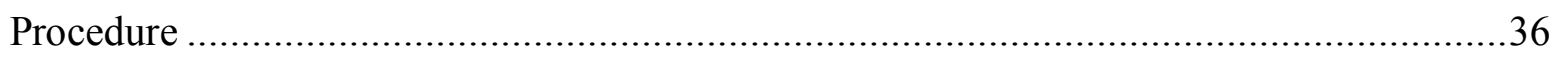




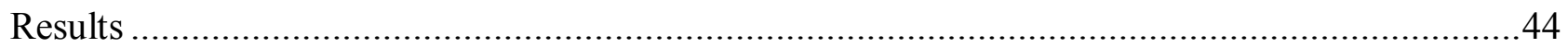

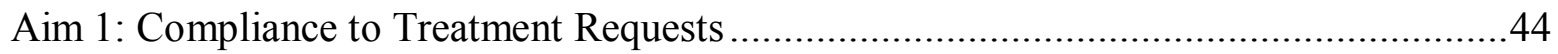

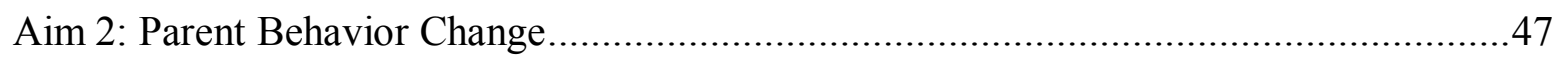

Aim 3: Parent Perceptions of Problem Behavior and Time Out Based Discipline Strategy .50

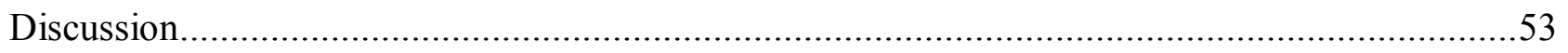

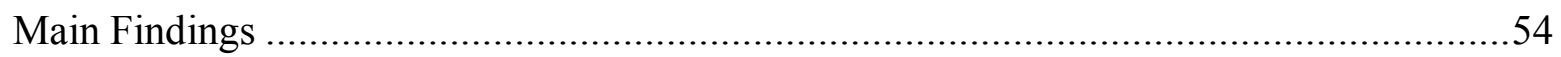

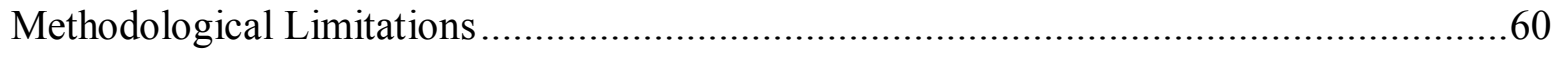

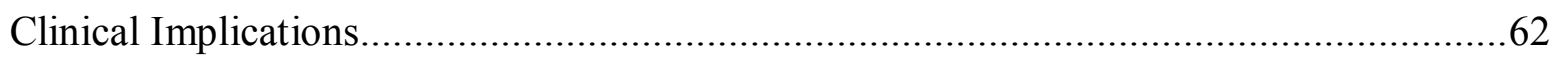

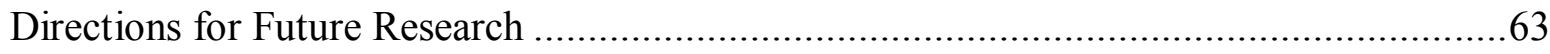

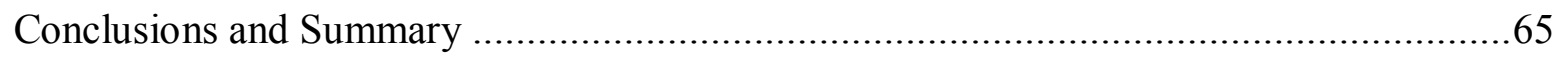

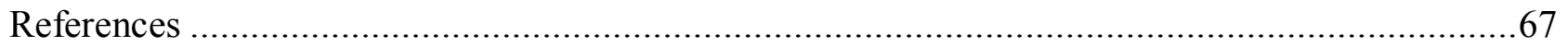

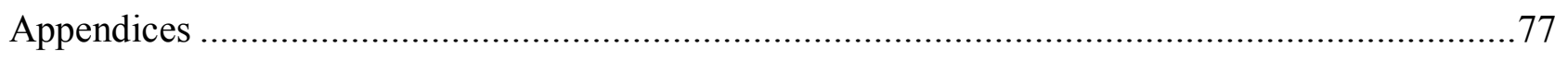

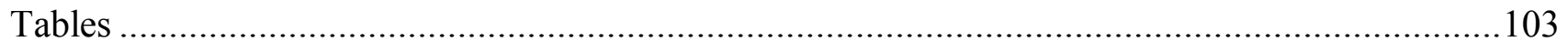

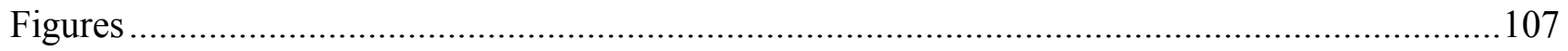


Evaluation of Time Out 1

Evaluation of Time Out Based Discipline Strategy to Manage Children's Noncompliance with Cystic Fibrosis Treatment

\section{Introduction}

Overview of Cystic Fibrosis and Treatment of Cystic Fibrosis

Cystic fibrosis (CF) occurs in 1 of 2,500 births in the U.S., making it one of the most common genetic diseases (Fitzsimmons, 1993). Found predominately in Caucasians, the majority of cases of CF are diagnosed by the age of four. CF is a progressive illness, characterized by abnormal mucus secretions, which primarily impacts functioning of the lungs and the pancreas. The build up of mucus in the lungs and pancreas ultimately leads to an early death, with an average expected lifespan of 30 years.

Treatment for $\mathrm{CF}$ includes medication, dietary changes, chest physiotherapy, and exercise. Some of the medications used to treat $\mathrm{CF}$ include antibiotics to prevent infection and enzymes taken with each meal and snack to improve nutrition; it is not uncommon for patients with CF to ingest 80 or more pills per day (Koocher, McGrath, \& Gudas, 1990). Because children with CF experience pancreatic dysfunction resulting in digestive difficulties and malabsorption of nutrients, they require $120 \%$ to $150 \%$ of the recommended daily allowance of calories for healthy children. Increased caloric intake is also necessary to maintain the sufficient energy balance needed to fight respiratory infections (Tomezsko, Stallings, \& Scanlin, 1992). Thus, people with CF are required to consume large quantities of high calorie and high fat foods. Chest physiotherapy (CPT), clapping vigorously on different sections of the patient's chest either manually or through the use of an electronic vest is performed to aid the patient in bringing up mucous from his or her airways. This improves and maintains lung functioning by preventing infection and obstruction in the airways. CPT is generally performed for 20 minutes one to four times daily. Exercise is a more 
recent treatment suggestion for CF treatment (Prasad \& Cerny, 2002). The goal of exercise is similar to that of CPT; specifically, it assists in the clearing of mucus, which prevents lung deterioration. This medical regimen and other medical advances in CF are likely responsible for the increase in mean life expectancy of individuals with CF from 12.8 years in 1975 to a projected life expectancy of 40 in 2001 (Jaffe \& Bush, 2001).

\section{Adherence to Cystic Fibrosis Medical Treatment Regimens}

The combined treatment components for CF represent a complex and physically strenuous regimen that can take hours each day for a child to complete (Drotar \& Ievers, 1994; Matthews \& Drotar, 1984). Adherence, which has been defined as “the extent to which a person's behavior (in terms of medications, following diets, or executing lifestyle changes) coincides with medical or health advice" (Haynes, 1979), plays a key role in the management of any chronic illness. Although treatment for CF does not offer a cure, adherence to the physician-prescribed treatment components slows the decline in lung functioning and increases longevity (Konstan, Byard, Hoppel, \& Davis, 1995; Patterson, Budd, Goetz, \& Warwick, 1993). Future treatment advances, such as gene therapy and lung transplantation, may present new opportunities for cures for these children; however, such treatments will be most effective in individuals who have not already developed irreversible lung damage (Jaffe \& Bush, 2001).

Put simply, it is essential both for current and future health status for individuals with CF to adhere to their treatment regimen. In addition to leading to serious health problems, medical nonadherence has been found to be a major cause of conflict in the families of individuals with CF (Patterson et al., 1993). In fact, it has been posited that improvements in adherence can lead to direct improvement in family functioning (Quittner, Drotar, Ievers-Landis, Seidner, \& Jacobsen, 2000). The financial considerations of non-adherence are also significant. Specifically, non- 
adherence to medical regimens can result in additional clinic visits, unused medications, and increased rates of hospitalizations. The cost of non-adherence (including adult and pediatric illnesses) in the United States is estimated at $\$ 100$ billion annually (Berg, Dischler, Wagner, Raia, \& Palmer-Shevlin, 1993).

Despite the health, family, and economic value of adherence to medical regimens, nonadherence rates for patients with chronic illnesses such as CF are especially high, ranging between 50 and 55\% (Rapoff \& Barnard, 1991). In populations with CF, adherence to medications has been found to be much higher than the rates of adherence to other treatment components, such as diet and CPT (Quittner et al., 2000). There are a number of factors that are associated with poor adherence to CF treatment. One such factor is parent and child understanding of the CF medical regimen, with greater comprehension of the regimen being associated with greater adherence (Ievers et al., 1999). Child age is another important factor, with younger children being more likely to demonstrated greater adherence (Ricker, Delameter, \& Hsu, 1998). More positive parent child interactions during treatment have been shown to be associated with increased treatment adherence (Stark et al., 2000). Another factor that can impact the degree to which CF treatment regimens are completed includes children's compliance to their parent's treatment requests. Researchers and clinicians alike have struggled to develop an operational definition of child compliance in a pediatric context. General child compliance has been defined as "The presence of an observable cue reflecting the initiation of a response within 5 seconds of the termination of the parental command or warning" (Forehand \& McMahon, 1981).

There exist many reasons why children with CF are noncompliant with their parent's treatment requests. For instance, the complex and aversive treatments contribute to difficulties following the medical recommendations. The delay in positive outcomes from treatment is another 
reason for pediatric noncompliance. This could explain the better adherence rates to antibiotics and medicines that offer more immediate relief than CPT and diet, which serve to prevent later negative consequences (e.g., lung deterioration, malnutrition). In fact, the preventive nature of much of CF treatment might make treatment seem unnecessary and unrewarding for both the caregiver and child (Gordis, Markowitz, \& Lilienfeld, 1969). In addition to treatment itself, there are individual characteristics that place children with $\mathrm{CF}$ at especially high risk of noncompliance to parent's treatment requests. Specifically, young age of diagnosis, frequent asymptomatic periods, and complexity of the treatment components are risk factors such noncompliance (Passero, Remor, \& Salomon, 1981; Rapoff \& Barnard, 1991). For instance, researchers have found that the quantity of treatment-related behavior problems are significantly higher for younger than older children (Sanders, Gravestock, Wanstall, \& Dunne, 1991), and that parents of children with CF report greater difficulty managing their child's treatment regimen when their child is healthy than when their child is ill (Eiser, Zoritch, Hiller, Havermans, \& Billig, 1995).

\section{Noncompliance to Treatment Requests and Family Functioning}

Given that life expectancy is largely dependent upon the treatment regimen, it is crucial that parents and their children work seamlessly together to administer the treatments effectively (Patterson, McCubbin, \& Warwick, 1990). Unfortunately, this is often not the case; research has demonstrated that a high proportion of parents report that their child resists CF treatment and engages in behaviors that interfere with treatment (Crist et al., 1994; Sanders et al., 1991). Research has suggested that the frequency and intensity of CF treatment regimens have been found to cause numerous disruptions in a family's functioning (Quittner, DiGirolamo, Jacobsen, \& Eigen, 1991; Thompson, Gustafson, Hamlett, \& Spock, 1992a, 1992b). For example, every meal with a child with $\mathrm{CF}$ can be a struggle for parents who must ensure that their child with $\mathrm{CF}$ is 
consuming enzyme pills and a high quantity of calories and fat (Ramsey, Farrell, \& Pencharz, 1992). Other research has shown connections between measures of maternal well-being and child treatment-related behavior problems, with increases in child behavior problems correlating with decreases in maternal well-being (Foster, Bryon, \& Eiser, 1998).

Additionally, families of children with CF must ensure that they can adapt their daily schedule to allow for CPT and other treatments. Treatment-related behavior problems are likely to impact a parent's ability to maintain the intense treatment required for CF management. In the worst-case scenario, parents of children who are consistently noncompliant with treatment requests become worn out to the point that that they cease treatment attempts. The more likely scenario entails parents devoting their energies to obtaining child compliance with treatment requests, and being less strict about their child's compliance to other requests, such as household chores or bedtime rules. Research investigating the behavior of children with CF supports the latter scenario (Ievers, Drotar, Dahms, Doershuk, \& Stern, 1994), with some researchers finding children with chronic illnesses being 2.4 times more likely than their physically-healthy peers to display diagnosable behavior disorders (Cadman, Boyle, Szatmari, \& Offord, 1987).

Parents also view misbehavior of physically ill children to be more excusable and less intentional than misbehavior of healthy or mentally ill children (Walker, Garber, \& Van Slyke, 1995). This tendency to excuse the misbehavior of physically ill children is increased when the child is younger (Dix, Ruble, Grusec, \& Nixon, 1986; Gretarsson \& Gelfand, 1988). The lack of appropriate discipline could lead to increased resistance to treatment demands. Furthermore, general noncompliance may relate to other future life difficulties (e.g., noncompliance in other settings such as at school, as well as difficulty obtaining and keeping occupations). Thus, for health and non-health issues, parents of children with chronic illness should use appropriate and 
consistent behavioral modification techniques for misbehavior, particularly noncompliance with parent's treatment requests.

Children's noncompliance to their parent's treatment requests could also lead to parents spending excessive time attempting to gain their children's compliance during treatment, thus increasing the quantity of time devoted to medical treatment. In an investigation of the mealtime behavior of children with $\mathrm{CF}$, researchers have concluded that parents of children with $\mathrm{CF}$, as compared to parents of physically-healthy children, reported engaging in higher rates of ineffective parenting strategies including coaxing the child to eat or preparing a second meal for the child to eat if they did not like the first meal (Powers et al., 2002). The use of these parenting strategies was found to be ineffective at obtaining increases in caloric intake. Further, this research has demonstrated higher rates of mealtime behavior problems in children with $\mathrm{CF}$ and that these behavior problems were associated with lower caloric intake.

Other research has revealed differences in the compliance of children with CF to the mealtime behavior commands of their parents, as compared to the compliance of physicallyhealthy children (Stark et al., 1995). Specifically, these children were less compliant with their parents' commands for them to eat. Interestingly, observations of parent behaviors revealed that similar to the findings of Crist et al., the parents of the children with CF issued a higher number of both direct and indirect commands. These parents also engaged in more coaxing and prompting of the child to eat, as well as actual feeding of the child as compared to families with physicallyhealthy children. In short, it appears that child noncompliance to parent's treatment requests and family functioning are reciprocal and form a negative feedback loop, with noncompliance serving to disrupt family functioning and problematic family interactions proving detrimental to $\mathrm{CF}$ treatment adherence. 
Interventions to Improve Adherence to Pediatric Medical Treatment

Research has demonstrated that the degree to which a child complies with their parent's treatment requests is an important contributing factor to determining overall adherence to a medical treatment regimen. Given that adherence to CF treatment is essential for optimal functioning and the only current means of prolonging life expectancy, research investigating methods to improve adherence is crucial. Currently, there exist few empirically supported interventions for children with CF who refuse to participate in their CF treatment regimen. Given the paucity of empirical investigations targeting child CF treatment noncompliance (Quittner et al., 2000), other research investigating treatment noncompliance to similar medical regimens will be included in the following review. For example, pill swallowing is a common treatment component for $\mathrm{CF}$ as well as other pediatric chronic illnesses. Thus, the following review will focus on interventions designed to decrease the treatment refusal behaviors of children with CF or other chronic illnesses whose medical regimens include components similar to those of the CF medical regimen.

Behavioral contracting. Behavioral contracting has been used to target children's noncompliance to their parent's CPT treatment request in patients with CF. In a case study design, Stark, Miller, Plienes, and Drabman (1987) used behavioral contracting with an 11-year-old girl with CF who was noncompliant with her parent's CPT treatment requests. The researchers helped the mother and child devise a contract whereby the child would earn treats, privileges, and activities in exchange for cooperatively participating in CPT treatments. They were able to demonstrate a significant improvement in the amount of CPT that she would cooperatively perform in exchange for these rewards. Further, these researchers found that the positive changes persisted for 6 weeks after the removal of the tangible rewards. The researchers hypothesized that 
a "reciprocal reinforcement style" had been set into place such that the girl was receiving positive attention from her mother even after the tangibles were removed. It was concluded that the positive attention was sufficient to promote adherence and cooperative CPT-related behaviors (Stark, Miller, Plienes, \& Drabman, 1987).

Token economy. Another behavior management strategy used by researchers to decrease noncompliance in children with chronic illnesses is a token economy. Greenan-Fowler, Powell, and Varni (1987) implemented a token economy to promote cooperation to therapeutic exercise for children with Hemophilia. As in the treatment of CF, exercise is an important component of the treatment for Hemophilia; however, the emphasis on exercise in the treatment of Hemophilia is to strengthen joints and to prevent joint bleeding, whereas exercise for CF is focused upon maintaining lung functioning. In their study, Greenan-Fowler et al. used a longitudinal, repeated measures design and included ten participants, ranging in age from 9 to 15 years old. The intervention consisted of having the participants track the exercises that they performed each day. The participants' parents verified the tracking sheets each day and at the end of the week the participants would attend a physical therapy group where the points could be exchanged for desired items. The researchers found that the token economy was initially quite successful at increasing child compliance with exercise regimen; however, when it was faded out the follow-up assessment revealed that rates of exercise dropped to nearly the baseline level (Greenan-Fowler, Powell, \& Varni, 1987).

Parents frequently complain that although their child will eventually perform the treatment regimen required of them, they must provide their child with constant reminders and supervision to ensure that the treatment is performed (Rapoff, Lindsley, Edwards, \& Christophersen, 1984). Rapoff et al. (1984) used a token economy to decrease the amount of parental coercion and 
supervision required for child compliance with the treatment of Juvenile Rheumatoid Arthritis (JRA) in a 7-year-old girl. The researchers implemented a multiple baseline across behaviors design to assess the impact of the token economy on each treatment component. The parents of the participant were taught to provide the child with tokens for complying with her treatment regimen (daily medications, wearing a splint, and resting on a firm surface each day) and removing the tokens for failure to comply with treatment requests. The tokens were later traded in for privileges such as special time with the parent or extra television time. Parents and the researcher assessed compliance with these treatment components via observation of the behaviors. The researchers introduced token reinforcements in a staggered fashion for each treatment component and were able to demonstrate control across treatment components. Interestingly, the parents also applied the token economy to non-treatment behaviors, such as household chores, but no data were kept on compliance with these tasks. The researchers found that they were able to significantly improve the child's compliance to parent's requests for all aspects of the treatment, and that these changes remained intact during the follow-up condition when the token economy was removed. The researchers hypothesized that the reason for the long lasting effect of the token economy was that it taught the parents to praise and reward compliance behaviors, and to minimize the attention that they paid to noncompliance behaviors by ceasing to nag, yell, or spank.

Close monitoring. Even simpler than behavioral contracting, token economies, and contingent reinforcement is close monitoring for noncompliance to parent's treatment requests. This intervention consists of parental tracking of the child's treatment behaviors as they occur. Rapoff et al. (1988) conducted a multiple baseline across subjects design to evaluate whether close monitoring of compliant behaviors would increase child compliance with parent's treatment requests. Participants were three female children with JRA ages 3, 10, and 13 years old. The 
researchers employed a single session to teach the parents and two older children to complete a recording form to monitor when the medications were taken each day. The researchers assessed treatment compliance by having the parents conduct weekly pill counts and a review of the monitoring sheets. Parents were also instructed to provide their child with positive verbal feedback for exhibiting good compliance with their treatment requests. This technique was shown to be effective for two out of the three participants; however, the four month follow-up compliance rates for one of these two participants was significant enough to indicate that a reversal of the intervention likely occurred (Rapoff, Purviance, \& Lindsley, 1988).

Multi-component treatment interventions. Package treatments involving multiple components have been used for a variety of child treatment noncompliance concerns. For instance, dietary management is a component of the CF treatment regimen with which there are high levels of child noncompliance with parental treatment requests (Stark, 2000). In an effort to improve adherence with this treatment component, Stark et al., conducted a series of single-subject, multiple baseline studies investigating treatment packages designed to increase calorie intake in children with CF (Stark, Bowen, Tyc, Evans, \& Passero, 1990; Stark et al., 1993; Stark, Powers, Jelalian, Rape, \& Miller, 1994). In all three studies, parents were taught to use the child behavior management strategy of differential attention - attending to appropriate eating behavior and ignoring non-eating behavior at mealtimes. The parents were also taught to use behavioral contracting. For example, the child could receive additional playtime with their parent contingent upon meeting their caloric intake goals. Two of the studies included additional components of nutrition education for the parents, as well as a child group where the contingency management strategies and nutrition information were taught to the children (Stark et al., 1990; Stark et al., 1993). In all three studies, the researchers demonstrated significant increases in the child's caloric 
intake and were able to demonstrate that the treatment gains persisted for up to 2 years postintervention.

In one of the few studies employing a group design to investigate a treatment intervention for $\mathrm{CF}$, Stark et al. compared nutrition education (NE) alone to nutrition education in conjunction with a behavioral intervention (BI) to reduce food refusal behaviors (Stark et al., 2003). A total of seven participants were randomly assigned to the NE group or BI group where in addition to the nutrition education the parents received training in child behavior management. The behavior management strategies included the use of differential attention, contingent privileges, and sticker charts to monitor and provide reinforcement for meeting caloric goals. All families were seen for a total of 7 sessions, and the dependent variables, caloric intake and child weight gains, were examined using a multiple baseline across meals design. The researchers found that the group receiving the nutrition education in conjunction with the behavioral intervention demonstrated the most gains in caloric intake and weight gain, and that the increase in caloric intake was maintained 2 years following treatment completion. This study is unique in that it not only included a comparison group, and a longitudinal design, but also examined the impact of the intervention for each child through the use of a multiple baseline across meal design. Such a design allows for comparison between groups as well as allowing each child to also serve as their own control. This study demonstrates the importance of considering child behavior and child behavior management when examining children's noncompliance with their parent's treatment requests.

Multicomponent behavior management interventions have also been employed for more severe feeding problems for children with CF in an inpatient setting. Using a case study design, researchers investigated the use of a combination of parent training, time out for negative behaviors, and positive reinforcement for food acceptance in 4 malnourished children with $\mathrm{CF}$ 
ranging in age from 10 to 42 months (Singer, Nofer, Benso-Szekely, \& Brooks, 1991). Feeding problems were assessed through a detailed parent interview which included an investigation of the history of the feeding difficulties, preferred foods, and details of parents' typical feeding procedures. Parent training included teaching the parents how to implement the basic principles of contingency management. The intervention included access to multiple reinforcers, such as stickers, praise, and preferred foods, following appropriate eating, as well as access to food only at specified mealtimes, and time out as a consequence for not eating. Outcome measures included quantity of calories consumed and weight gained. Hospital staff initially implemented these interventions with the children, and once consistent oral intake was established, parents were expected to carry out the procedures. Results indicated that the intervention was effective in increasing calorie consumption and weight in 3 of the 4 participants, and that the increases in weight persisted to the 15 month follow-up check-up. While these results are encouraging, a practical limitation of this research is that it required an initial hospitalization and a large amount of medical staff time prior to teaching the parents. Additionally, because the research included so many treatment components, it is difficult to determine which components were the most important in promoting increased child eating.

While research investigating caloric intake in children with CF is important, the benefits of the nutritional intake will not occur if the child refuses to take their enzyme medications. As such, pill swallowing is an important component of many treatment regimens for chronically ill children, and certainly an important treatment component of CF. Pelco et al. (1987) conducted a multiple case-study investigation to determine the efficacy of a combination of behavior management strategies in addressing treatment refusal in 2 two-year-old chronically ill children who were noncompliant with requests to swallow medication in pill form. For one child, the intervention 
consisted of verbal instruction, modeling, shaping, and contingent reinforcement. For the second child, the same techniques were implemented along with physical guidance for noncompliance. For both children, the combination of these techniques resulted in the child swallowing pills of increasingly larger sizes upon requests, and these treatment gains persisted for the follow-up assessment 6 months later (Pelco, Kissel, Parrish, \& Miltenberger, 1987).

Also investigating pill swallowing, Babbitt et al. (1991) used similar behavior management techniques as those used by Pelco et al. (1987). The researchers used a nonconcurrent multiple baseline across subjects, single-subject design to assess the effectiveness of a behavior management technique to develop independent swallowing of increasingly large capsules. Participants were four developmentally-delayed children with chronic illnesses ranging in age from 3 to 17 years. In addition to the use of verbal instruction, shaping, and contingent reinforcement, the researchers also used a time out procedure for one participant if she refused to swallow any pills during the training session and for another participant if he chewed or refused to swallow his pills. This time out procedure consisted of having the child sit in a chair and involved the removal of the trainer's attention and any toys that may have been in the room. Control across participants was noted, in that none of the participants accepted pills during the baseline condition. The researchers found that at follow-up the children were rarely noncompliant with requests to swallow their medication (Babbitt, Parrish, Brierley, \& Kohr, 1991).

Similar to medications, breathing treatments comprise an important component of CF treatment which children often find uncomfortable and frequently resist. While breathing treatments are essential for management of $\mathrm{CF}$, there is a paucity of research investigating this treatment component. Similarly, while addressing CF treatment refusal in children with developmental-delays is an important area of concern, there is a lack of empirical investigations 
exploring this area. To explore these two topics in conjunction, researchers employed a single subject, reversal design to investigate a shaping and escape procedure to decrease treatment refusal in an 8-year old boy with CF, mental retardation, and autism (Hagopian \& Thompson, 1999). Specifically, inhaler mask acceptance was shaped up by rewarding mask acceptance with a 60 second period in which the child was given social praise and access to preferred rewards. When the child exhibited any aggressive or avoidant behaviors, an escape procedure was implemented by ending intervention period immediately and following it with a 60 second period in which the child received no attention and no access to rewards. The results indicated that the intervention was effective at eliminating the child's treatment noncompliance. During the reversal phase, the child's aggressive and avoidant behaviors returned to the baseline rate. These findings suggest that research employing removal of attention in combination with praise and rewards is effective at increasing compliance with inhaler mask treatments, which are relatively nonaversive and noninvasive. It would be important to determine whether these same interventions would be effective at increasing compliance with other CF treatment components, such as CPT or pill acceptance.

\section{Summary and Critique of the Literature}

In sum, the research investigating interventions to improve child compliance with treatment requests has demonstrated that multiple strategies exist to increase child compliance with parent treatment requests. Some treatments, such as contingent reinforcement and home-based token economies, were found to have longer lasting effects than others, such as close monitoring and clinic-based token economies. One difficulty in interpreting the findings of these studies is that many of them included a large number of treatment components. For example, in the series of studies on mealtime behaviors, Stark and colleagues included the following treatments: differential 
attention, contingent privileges, and setting realistic expectations at mealtimes. Thus, it is difficult to identify the active treatment components and the treatment might be unnecessarily long and difficult. For example, the intervention used by Stark et al. (1994) required that the families attend 6 to 9 weekly sessions that were each 90 minutes in length.

In addition to being complicated and difficult to learn, some of the interventions were individually tailored and not easily adapted to other treatment components. For example, if a parent decided to modify a token economy to a different component of their child's treatment regimen, they would have to define the behaviors of interest, assign the behavior points, and explain the new system to the child. Further, the token system would have to be significantly altered as the child aged to be sure that the child would still find the tokens sufficiently reinforcing. Although this form of adaptation is not beyond the abilities of a typical parent, a simpler parenting strategy that could be quickly adapted to a range of treatment and non-treatment compliance issues might be preferable.

Much of the adherence promotion literature is very specific, focusing upon increasing child treatment compliance in one or two areas of the child's treatment. Although this can affect change in that area for the child, a broader and more flexible program would help parents deal with child treatment noncompliance in a range of areas and provide tools to promote compliance to treatment requests as the problem arises. When examining the commonalities among the programs that were effective, it appears that a few essential components can be identified. First, the program needs to be one that is home based. When comparing the token economy programs implemented by Greenan-Fowler et al. (1987) to the one used by Rapoff et al. (1988), the only significant difference is that in the Greenan-Fowler study, the procedure was being implemented by the parents, and for the Rapoff study, the researchers were delivering the rewards. Eiser et al. (1995) 
concluded that rather than prepare parents for the objections that their children might raise to $\mathrm{CF}$ treatment, clinicians should teach parents home-based skills that focus on the mechanics of implementing care.

A final critique of this research is that only one of the studies employed a reversal or a component analysis type design (Hagopian \& Thompson, 1999). Without a method of demonstrating that the intervention has functional control, it may be difficult to truly determine the effect of the intervention and to separate out the effect of the intervention from other possible factors such as maturation.

\section{Time Out to Increase Child Compliance with Cystic Fibrosis Treatment Requests}

In sum, research has demonstrated that a variety of behavior management techniques can effectively increase compliance behaviors in children with chronic illnesses. One child management strategy that was rarely utilized in the child treatment compliance literature is time out. Only two studies employed this technique, and one used time out as a back up technique when other behavior management techniques were not sufficient (Babbitt et al., 1991). In both of these studies, the time out procedure employed was found to be effective in increasing compliance in developmentally-delayed children who were initially noncompliant with their parent's treatment requests. The paucity of evaluations of time out for child noncompliance with parents' treatment requests is surprising given that time out is one of the most widely used interventions for decreasing maladaptive behavior, and, along with removal of privileges, one of only two recommended discipline strategies by the American Academy of Pediatrics (American Academy of Pediatrics, 1998; Mace \& Heller, 1990). In terms of parent perceptions of time out, a survey revealed that parents find time out to be a highly acceptable form of discipline (Mace \& Heller, 1990; Socolar \& Stein, 1996). Further, in his chapter reviewing strategies to improve child 
compliance with medical treatment for children with chronic illnesses, Rapoff (1999)

recommended time out as one of only two interventions for parents to use with noncompliant children. Although time out is a recommended behavioral treatment for child treatment noncompliance, it has not been adequately evaluated in this regard.

Possible explanations for the lack of research investigating the efficacy of time out to decrease child treatment noncompliance include possible misconceptions surrounding time out procedures and the function of children's treatment noncompliance. It has been assumed in the field of psychology that the function of a child's treatment noncompliance is to escape or avoid the treatment (Stark et al., 1993). Thus, time out procedures might negatively reinforce children's escape or avoidance of treatment (Handen, Parrish, McClung, Kerwin, \& Evans, 1992; Stark et al., 1993). This critique is valid if the child prefers being in time out to completing treatment or the child is not required to complete the treatment at the end of the time out. However, if the child is required to complete treatment immediately following time out and the child finds time out to be more aversive than completing the treatment, a time out program should effectively increase adherence.

Time out based discipline strategies for child noncompliance to parental requests are common in many well-established parenting programs; Forehand's parenting program (Forehand \& McMahon, 1981), Patterson's parenting program (Forgatch, 1991), and Parent-Child Interaction Therapy (Hembree-Kigin \& McNeil, 1995) all include time out. Research evaluating the components of parenting programs has found time out to be the crucial component for decreasing child noncompliant behavior (Eisenstadt, Eyberg, McNeil, Newcomb, \& Funderberk, 1993; Roberts, Hatzenbuehler, \& Bean, 1981). 
Although there is variation in the steps of the time out procedures, the general components of a time out based discipline strategy are similar. Specifically, parents are taught to provide their children with direct concise and single commands, to give the child a specified amount of time to comply, and to praise compliance when it occurs. If the child does not comply with the parent's request within the designated amount of time, the parent provides the child with a clear warning indicating that the child must comply or take a time out. Should the child persist with his or her noncompliance, the parent places the child in a brief time out whereby the child is removed from both parental attention and reinforcing stimuli. Following the time out, the parent re-issues the original command, with a second time out used if noncompliance continues. It is expected that the child will eventually comply with the command to avoid receiving repeated time outs, and over time the child should learn to comply promptly to avoid time out entirely.

Time out based discipline strategies have been used to manage children's behaviors in a variety of non-medical settings. Researchers investigating the efficacy of a time out based discipline strategy as compared to no intervention have found that parents in the time out group report significant reductions in their child's noncompliant behavior (Hamilton \& MacQuiddy, 1984). Rortvedt and Miltenberger conducted a single-subject investigation of time out based discipline strategy with two 4-year-old children. The researchers compared time out and behavioral momentum for noncompliance to parental requests. Behavioral momentum consisted of the parents issuing a series of high-probability requests with which the child is very likely to comply followed by a low-probability request. The researchers found that whereas the time out package was effective in increasing compliance with both participants, behavioral momentum was only effective for one of the participants (Rortvedt \& Miltenberger, 1994). 
The efficacy of time out has also been examined by comparing it to other child management strategies, such as guided compliance. Using guided compliance, a parent would physically guide the child through the specific task if they initially refused to comply with the parent's request. Handen et al. (1992) compared these two strategies with five mildly delayed children ranging in age from three to six years. The researchers used a variation of the time out procedure whereby the child did not have to complete the original request at the end of the time out; instead, they were given a new request. The researchers concluded that time out was more effective at increasing compliance than the guided compliance technique for four of the five participants.

Researchers have also evaluated time out for adolescents with developmental-delays. Specifically, when the adolescents displayed noncompliance with their teacher's requests, they were restricted from access to leisure time activities including listening to the radio and looking at a magazine. Once the problem behaviors ceased, the researchers allowed the adolescents to access the radio and magazines again. The researchers found that this time out procedure was more effective than differential reinforcement of other behavior (DRO) at reducing problem behaviors during leisure activities (Haring \& Kennedy, 1990). In sum, a review of the time out literature demonstrates this technique to be effective across a range of populations and problems. However, a time out based discipline strategy that includes positive reinforcement for compliance and removal of attention for noncompliance has not been adequately examined in terms of its efficacy for increasing adherence to pediatric medical regimens.

\section{Purpose of Study}

The purpose of the study was to use a single-subject reversal design to examine the effectiveness of a time out based discipline strategy at increasing compliance to parents' treatment 
requests in children with $\mathrm{CF}$. The time out based discipline strategy in the current study included praise for compliance and a time out from parental attention for noncompliance. Several researchers have concluded that single-subject designs represent the best method with which to evaluate treatment of pediatric illnesses as they allow for the researcher to assess the intervention efficacy on an individual basis (Lemanek, Kamps, \& Chung, 2001; Rapoff, 1999). In the current project, parents' typical parenting strategies during baseline were compared to the time out based discipline strategy to evaluate whether the time out package increased child compliance to parents' treatment requests. The Functional Assessment Structured Interview was conducted to determine the function of the child's treatment related behavior problems. Parents also completed the Background Information Form to provide demographic information and a Behavior Assessment System for Children (BASC) to provide information on how their child compared to a normative population. At the start of each study condition, parents completed the Cystic Fibrosis Problem Checklist to provide data on the intensity and the frequency of their child's treatment related behavior problems. An Observational Assessment tool was employed to code parent and child interactions during the video recorded treatment observations. To ensure that the parents understood the time out intervention, they completed a Time Out Quiz at the start of each intervention condition, and their implementation of the intervention was monitored with a Treatment Integrity measure. Finally, at the completion of the study parents and their child participated individual in the Parent Exit Interview and the Child Exit Interview. As part of the study, the time out procedure was removed and later reinstated to help rule out confounds such as maturation or historical events.

Study Aims 
Aim one: Compliance with treatment requests. It was hypothesized that the time out based discipline strategy would effectively increase children's compliance to parents' treatment requests. Specifically, children were expected to exhibit greater percentages of compliance to parents' treatment requests (direct and indirect commands) in the intervention conditions than during the baseline or reversal conditions. In addition, it was expected that the probability of child compliance would increase in the presence of specific parent behaviors. In other words, the probability of child compliance within 5 seconds of parents' direct commands, indirect commands, and labeled praise was expected to increase during the intervention conditions and not during the baseline or reversal conditions.

Aim two: Parent behavior change. It was hypothesized that in the intervention conditions, increases would occur in the percentage of direct commands relative to the total number of direct and indirect commands, and in the percentage of labeled praise relative to the total number of labeled and unlabeled praise. Further, during the intervention conditions, the percentage of desirable parent behaviors relative to the total number of parent behaviors was expected to increase and the percentage of undesirable parent behaviors relative to the total number of parent behaviors was expected to decrease. Specifically, during intervention, parents were expected to engage in higher percentages of labeled praise and direct commands, and lower rates of negative verbal and physical attention than during baseline or reversal.

Aim three: Parent perceptions of problem behavior and time out intervention. It was expected that the increased treatment compliance would also be apparent when examining changes on the paper and pencil report of the children's targeted treatment-related problem behaviors. Specifically, it was expected that parents would report greater child compliance upon completion of the two intervention conditions as compared to their report of child compliance at the start of the 
study and at the end of the baseline conditions. Finally, it was expected that upon completion of their participation in the study, parents would indicate that they prefer the time out child management strategy to their typical child management strategy.

\section{Method}

\section{Participants}

Two children with CF participated in this study. Inclusion criteria required that the child be at least $50 \%$ noncompliant with one parent-initiated daily $\mathrm{CF}$ treatment component. Participants with developmental disabilities such as mental retardation, autism, and Down syndrome, or diagnoses of severe psychopathology, such as Post-Traumatic Stress Disorder or Major Depressive Disorder were excluded from participation, as these disorders could confound the findings and complicate comparisons across participants. If at any point during the study, the experimenter had discovered any significant psychopathology or child abuse or neglect, appropriate reporting and referrals would have been made and study participation terminated. Such abuse or neglect was not found to occur in the families of any of the participants in the study. Finally, children in treatment for general noncompliance or oppositional behavior were excluded because overlap between the two interventions could have made it difficult to determine whether behavior changes were related to the current study or to the ongoing treatment. Parents who reported employing a time out procedure as their typical child management strategy were also excluded from participation if the strategy included $50 \%$ or more of the same components of the proposed time out based discipline strategy (see Appendix A, e.g., no attention given during time out, child required to complete original and second task upon completion of time out). 
The first participant, Mary Smith (pseudonym) was a 4 1/2-year-old Caucasian female from a rural community in the northeastern United States. Mary lived with both of her biological parents, Mr. and Mrs. Smith, and her 12-year-old half brother who had been diagnosed with autism. Prior to Mary's birth, Mrs. Smith had participated in behaviorally oriented training program to encourage adaptive behavior in her son. At the time of the study, Mrs. Smith was not participating in any training for her son's behavior. Both of Mary's parents had completed high school, and her mother was a homemaker and her father worked in the timber industry as a logger. Mary had been diagnosed with CF when she was approximately 3 years old, and had never been hospitalized. Her treatment regimen consisted of the use of a vest airway clearance system for CPT two times per day, nebulizer treatments two times a day, enzyme pills with every meal and snack, as well as liquid vitamins and laxative one time per day. Mrs. Smith was Mary's primary caregiver and reported that she was responsible for providing Mary's treatments approximately $90 \%$ of the time, and her husband provided the remaining $10 \%$ of the treatments.

Mrs. Smith reported that since her diagnosis, Mary had engaged in a variety of treatmentrelated behavior problems. These included hiding her pills rather than taking them, "strategically" choosing food and drink that were difficult to mix with her enzymes, and stating that she had taken her pills when she had not. Mrs. Smith reported that in addition to difficulty with her pills, Mary exhibited a number of treatment-related behavior problems surrounding her CPT vest treatments, including pulling the hoses loose on her CPT vest, moving around excessively during treatment, and attempting to avoid CPT treatments by running away or arguing with her mother when called to the treatment. After reviewing the results of Mrs. Smith's responses on the CFPC, it became clear that the behavior problems associated with her 
CPT were of central concern to Mrs. Smith. As such, it was decided that Mary's refusal to participate in CPT treatment would be targeted in this study.

A functional assessment of Mary's CPT vest treatment refusal was conducted through the use of a structured interview (Appendix B). The specific problem behaviors that Mary engaged in when her mother approached her for CPT vest treatment included verbal refusal, whining, and running away. Mrs. Smith reported that when Mary participated in this refusal, she did not typically chase her. Rather, she generally stayed on the couch and would yell at Mary or very rarely get up to bring her to the living room for the treatment. It was determined that the function of this behavior was to avoid her CPT treatment, however, due to the intermittent reinforcement provided to Mary by her mother's occasional provision of attention, there may have been an attentional component that contributed to maintaining Mary's avoidance behaviors. Mary's mother reported that these behaviors occurred approximately $80 \%$ (verbal refusal, whining) to $30 \%$ (running away) of the time, and lasted anywhere from 15 seconds to the duration of the treatment, approximately 45 minutes. On a scale of 0 to 10 , with 0 being that the behavior had no impact and 10 being that the behavior had a large impact upon treatment implementation; Mrs. Smith ranked these behaviors in the 7 to 8 range.

Factors that aggravated Mary's treatment refusal included a lack of sleep, being off schedule, and being involved in other engaging activities such as creative play. Factors that decreased Mary's treatment refusal included having other children present during treatment time, getting to watch TV or hear a story during treatment, the time of day that treatment was given, whether her father delivered the treatment, and treatments delivered when her father and brother were away from the home. Mrs. Smith reported that her typical child management strategies included yelling at Mary, turning off the television to get Mary's attention, and telling Mary to 
stop running away or whining. Mrs. Smith reported that she often felt guilty when she disciplined Mary for her treatment noncompliance because Mary had been born with her illness and would have to participate in treatment her entire life. As a reward for good treatment cooperation, Mrs. Smith reported that they would allow Mary to feed the family fish or play with special toys. Reportedly, these strategies were ineffective.

The second participant, Janis Doe (pseudonym) was a 5-year-old Caucasian female also from a rural community in the northeastern United States. Janis lived with both of her biological parents, Mr. and Mrs. Doe, and had no other siblings or family members living at the home. Janis' mother had earned a Masters Degree and was working as a computer education teacher at her local elementary school, while her father had completed high school and was a construction laborer. Mrs. Doe had previously taught computer education at a community college and had recently, approximately 2 years previously, began teaching at the elementary level. As part of her teaching at the elementary school, Mrs. Doe taught a section of special education students and had received training to teach this class approximately a year and a half prior to her participation in the current study and had been teaching a special education class for approximately one year. Janis had been diagnosed with CF when she was approximately 4 weeks old and had been hospitalized on multiple occasions for illnesses and for surgeries including the insertion of a gastrostomy tube for feeding. Janis' treatment regimen consisted of the use of a vest airway clearance system for CPT two times per day, nebulizer treatments two times a day, enzyme pills with every meal and snack, and nighttime feedings through her gastrostomy tube. Mrs. Doe was Janis' primary caregiver and reported that she was responsible for providing Janis' treatments approximately $60 \%$ of the time, and Janis' maternal grandmother and Mr. Doe provided her treatments the remaining $40 \%$ of the time. 
Mrs. Doe reported that since Janis had been old enough to swallow her enzyme pills, approximately 2 years of age, she had refused to accept the pills. When her parents had first attempted to teach her to swallow her medications, she had several episodes in which she gagged and vomited the food that she had ingested. Mrs. Doe also noted that Janis' aunt, an individual who played a prominent role in Janis' life, also refused to swallow pills. She noted that Janis' aunt's pill refusal was well known in the family and that Janis herself had witnessed several events in which a topic of focus was her aunt's pill refusal. Several modifications had been made to Janis' treatment regimen to accommodate her pill refusal. A major modification, which was primarily related to her difficulty meeting her high daily caloric needs, involved having a gastrostomy tube surgically implanted. With the nighttime feedings, Janis' caloric and enzyme needs were largely met; however, she remained underweight, and was described by her mother as a selective eater who ate only small quantities of specific foods.

An additional modification to her treatment plan was made by her parents and medical team to ensure that she did get some quantity of enzyme medication with the snacks and small meals that she did eat. Specifically, her parents would attempt to sprinkle enzyme on her food when possible to ensure that the nutrients in those meals and snacks would be absorbed. This modification was hampered by the fact that Janis would refuse to eat the majority of the foods sprinkled with enzyme and often selected foods that were difficult to sprinkle with enzymes, such as cheese and crackers or an apple. In fact, Janis only cooperated with eating two foods, which were sprinkled with enzymes: pancakes and McDonalds parfaits. If Janis was aware that any other foods contained enzymes, she engaged in a variety of problem behaviors, including food refusal, crying, yelling, running away, and withdrawing from her parents for several hours. These behaviors were reportedly distressing to her parents, who were concerned about Janis' 
food intake and her emotional state. Other than refusing to eat foods sprinkled with enzyme and refusing to swallow her pills, Janis participated actively in all other components of her treatment.

After reviewing the results of Mrs. Doe's responses on the CFPC, it was decided that Janis' enzyme pill refusal would be targeted in this study as it represented the most significant treatment refusal behavior problem. One factor that related to making this a pressing concern for the Doe family was the fact that Janis was to start kindergarten the next year. Mrs. Doe was concerned that it would not be feasible for Janis' teacher to sprinkle enzyme medication upon the lunch and snacks that she ate during the day. Thus, she was seeking a more effective method of helping Janis ingest her enzymes. Additionally, Janis had repeatedly expressed to her mother that she did not like her gastrostomy tube and wanted to have it removed. For this to be achieved, Janis would have to find a method of consuming her enzyme pills at mealtimes so that she could absorb the nutrients.

A functional assessment of Janis' enzyme refusal was conducted through the use of a structured interview (Appendix B). Because of her difficulty and refusal to swallow pills, the Doe's no longer offered pills to Janis. Therefore, the functional assessment focused upon her refusal to eat foods sprinkled with enzymes. Although this behavior was not ultimately the targeted behavior in the study, the results of Janis' functional assessment are described below to shed light upon her treatment refusal behavior. The specific problem behaviors that Janis engaged in when her mother attempted to sprinkle enzyme on foods included verbal refusal "You know I won't eat that!" crying, running away, and becoming emotionally distressed. Mrs. Doe reported that similar behaviors consistently occurred when they had attempted to have Janis swallow the pills, and as a result they had given up attempts to have Janis swallow her pills 3 years earlier. Additionally, Mrs. Doe reported that when asked about her pill refusal Janis had 
told her mother that she was afraid that she would choke if she tried to swallow pills. Mrs. Doe reported that the frequency of the refusal varied as to the degree to which the enzymes were apparent in the food, but given the gritty texture of the medication, Janis almost always noticed the enzyme medications. As such, her parents primarily sprinkled the enzymes on pancakes or McDonald's Parfaits. On the occasions that Mrs. Doe had attempted to place the medications in other foods, Janis would cry approximately $90 \%$ of the time, and run away approximately $50 \%$ of the time. Mrs. Doe reported that her crying could "go on forever" and that she and Mr. Doe would rate it as "intolerable" or "above a 10 " on a scale of 0 to 10 . It was determined that the function of Janis' treatment refusal behavior was to avoid her enzyme medication.

Factors that aggravated Janis' treatment-related behavior problems included a lack of sleep, variation in the order of her breathing treatments and nighttime routine, and when her grandmother and father encouraged her to eat food with enzymes. Mrs. Doe reported that there were no factors that improved Janis' treatment-related behavior problems, and that setting and time played no role in influencing her refusal. Mrs. Doe reported that her typical child management strategies included taking away privileges or toys, or speaking to Janis in a calm manner with an "adult" voice that Janis enjoyed. Neither of these strategies was successful. Additionally, Mrs. Doe reported that she felt anxious and guilty when she punished Janis for refusing to eat enzyme sprinkled foods. Specifically, she reported that she worried that by punishing Janis for food refusal she might inadvertently increase Janis' feeding difficulties. Additionally, she reported that she felt guilty insisting that Janis eat these foods because of the gritty and unappetizing texture of food that had been sprinkled with enzyme.

In selecting a specific target treatment goal, Janis' parents agreed that swallowing her entire enzyme pill would be both unreasonable and undesirable. Specifically, her parents were 
concerned that by disciplining Janis for refusing to swallow her entire pill they might unintentionally increase her pill related anxiety and the age at which she would accept her enzyme medication in a pill form. Several alternative goals were considered, including facilitating pill acceptance through a specially designed cup and smaller sized enzyme pills. Because enzyme pills are comprised of loose medication in a gel cap it was not possible to reduce the size of this pill. Given Janis' history of a gag and vomit reactions when she attempted to take pills, it was agreed that requiring her to swallow an entire enzyme pill presented an ethical concern as she could choke.

An alternative goal of having Janis consume her enzyme medications in a spoonful of caramel syrup was agreed upon. This method represented an improvement over the current situation as her parents could be assured that she had ingested the entire contents of her enzyme pill, whereas when enzymes were sprinkled on Janis' food she often did not consume all of her food and therefore did not consume all of her medication. During baseline assessment of this treatment goal, Janis' was slightly more than 50\% compliant with her mother's requests to consume the medication on the spoon. As such, she no longer met criteria for participation in the study.

Termination of Janis as a research participant was considered; however Mrs. Doe reported concerns about the practicality of the spoon method of enzyme consumption when the family traveled and when Janis entered school the following year. In addition, Mrs. Doe wanted to target pill swallowing. As such, a new goal was considered whereby Janis' refusal to swallow pills could be addressed. Because it was not possible to reduce the size of the enzyme pills by cutting them, it was agreed that an assessment would be conducted whereby Janis would "practice" swallowing imitation pills (i.e., small pieces of hard candy), with the eventual goal of 
her building up to larger pieces and actual pills following the completion of her participation in the study. The assessment revealed that Janis complied with her mother's requests to swallow the small candy "pills" $0 \%$ of the time, and thus, she met criteria and was entered into the current research study.

Measures

Treatment integrity measure (Appendix A). The experimenter (CBM) evaluated the first three intervention observations using the Time out Treatment Integrity Check form to determine whether the parent was implementing the steps of the time out based discipline strategy accurately. This form contains a series of questions that indicate whether the person is or is not conducting the time out based discipline strategy in accord with training. Treatment integrity was calculated for the three combined sessions. The parent was considered to be adherent if he/she met at least $75 \%$ of the time out based discipline strategy criteria.

Functional assessment (Appendix B). A functional assessment was used to identify the events that hinder child compliance to parent-initiated treatment requests, to obtain an operational definition of the child's treatment refusal, and to help with interpretation of results. This technique has been successfully employed to determine the barriers to compliance with pediatric illnesses such as Insulin-Dependent Diabetes and Juvenile Rheumatoid Arthritis (Rapoff, 1999). Functional assessments can include various modalities, and the current approach involved a structured interview modeled upon the technique proposed by O’Neil (O'Neil, Horner, Albin, Storey, \& Sprague, 1990). The purpose of the interview was to identify the antecedents and consequences that maintained child treatment refusal. As part of the functional assessment, the parent was also asked about the strategies he or she typically employed to obtain child compliance with each component of the treatment regimen. The function of the treatment 
refusal was determined by categorizing each behavior into one of three categories: to obtain desirable events, to avoid undesirable events, or to escape undesirable events (O'Neil et al., 1990). Two graduate students independently categorized functions of the children's behaviors, and their agreement was compared. Had it not been possible to agree upon the function of a particular behavior, the behavior would have been presented to an impartial Behavior Analyst for clarification; however, this was not necessary.

Background information form (Appendix C). The background information form consisted of questions assessing parent age, gender, education level, occupation, spouse education and occupation, total family income, and parent relation to the target child. This form also contained questions to assess the number of other children in the home, as well as their ages, gender, and the age and gender of the target child. Finally, parents answered questions about the target child's chronic illness, including the age at which the child was initially diagnosed, the number of hospitalizations the child has experienced, whether the child has experienced any other serious illnesses, the components of CF treatment that the parent has difficulty obtaining child cooperation with, and the physician-prescribed treatment regimen. This form also provided some basic demographics to evaluate inclusion criteria and allow comparisons across participants.

Behavioral Assessment System for Children - Parent Rating Scale for Children (BASCPRS-C). The BASC-PRS-C (Reynolds \& Kamphaus, 1992) is a parent report measure designed to assess child functioning within emotional and behavioral domains. The preschool version of the BASC-PRS-C can be used for children ages $2 \frac{1}{2}$ to 5 years old and contains 131 items. The BASC-PRS-C contains clinical scales, adaptive scales, and validity indexes, and takes approximately 15 minutes to complete. Parents responded to questions about child behavior on a 4-point scale from never (0) to almost always (4). The BASC-PRS-C was normed on a sample 
representative of the general U.S. population (Merenda, 1996), has separate norms for male and female parent reports, and for children with emotional or behavioral problems. The BASC-PRSC yields standardized scores on 13 scales (Aggression, Anxiety, Attention Problems, Atypicality, Conduct Problems, Depression, Hyperactivity, Learning Problems, Somatization, Withdrawal, Adaptability, Leadership, and Social Skills), and 4 composites (Internalizing Problems, Externalizing Problems, Behavioral Symptom Index, and Adaptive Skills).

Research has demonstrated that the BASC-PRS-C has good convergent and criterionrelated validity (Doyle, Ostrander, Skare, Crosby, \& August, 1997), good internal consistency (Merenda, 1996), and good test-retest reliability (Reynolds \& Kamphaus, 1992). Parents completed the BASC-PRS-C as part of the initial assessment during the baseline condition, and at the end of the study to provide descriptive information about their children. In addition, the BASC-PRS-C allowed for additional interpretations and explanations of results.

Cystic Fibrosis Problem Checklist (Appendix D). The Cystic Fibrosis Problem Checklist (CFPC; Sanders et al., 1991) is a 34-item checklist that assesses parent perspective of the difficulties their child experiences with CF treatment. The measure includes questions assessing difficulties associated with specific treatment components (CPT, diet, medication) in addition to the parent perspective of how the child and their entire family is impacted by CF, and questions assessing children's responses to hospitalization experiences. For each item, the parent rates, on a 5-point scale ranging from "Not at all" to "Very Much," how well the item describes their experience in the past 7 days. These items are averaged for each treatment component to create a mean problem intensity score. Next to each item there is a box for the parent to indicate whether they desire help for the problem represented by that particular item. The numbers of items endorsed are then averaged to create a problem item score. Research has demonstrated that this 
measure is reliable and a factor analysis has revealed the following 5 subscales: Physiotherapy, Mealtime/Diet, Medication, Emotional/Communication, and Hospital related (Sanders et al., 1991). For the purposes of the current study, only the following subscales were examined: Physiotherapy, Mealtime/Diet, and Medication. In order to evaluate changes in parents' perceptions of CF treatment problems, this measure was administered five times - pre-baseline, post-baseline, post-intervention, post-reversal, and completion,

Observational assessment (Appendix E). Videotaped time out procedures were coded to determine the parent's verbal and physical behaviors utilized during child management, child compliance with parent's treatment requests, and the frequency and quality of the time out procedures. All parent, child, and procedure codes were coded as present or absent on partial interval coding system across five-second intervals. The parent behaviors codes include both verbal and physical categories. The parent verbal behaviors include direct command, indirect command, labeled praise, unlabeled praise, negative verbal attention, and general verbal attention. The first 4 parent verbal behaviors represent slight modification of behaviors included in the Dyadic Parent-Child Interaction Coding System (Robinson \& Eyberg, 1981), which has been used widely in both research and clinical work to assess parenting skills, and to track parent and child behavior change resulting from parent training. Parent physical behaviors include physical guidance, prompt, physical negative, physical positive, and tangible delivery. Child behaviors include compliance, problem behaviors, cry, and leave time out. Finally, the onset and end of time out procedures was coded so that parental behavior during time out could be assessed.

Several variables were calculated from the observational assessment data. The first dependent variable derived from the observational assessment codes of interest was the 
percentage of child compliance, calculated by dividing the number of times the child complies with a parental treatment request (i.e., direct command, indirect commands, and prompts) by the total number of intervals of parental treatment requests. A second dependent variable calculated from the observational assessment was the percentage of direct commands given by the parent to the child. This was calculated by dividing the number of direct commands by the total number of commands (direct and indirect). A third dependent variable calculated from the observational assessment was the percentage of labeled praise the parent gave to the child, calculated by dividing the number of labeled praises by the combined number of labeled and unlabeled praises. A fourth variable was the overall percentage of compliance behaviors praised, calculated by the number of child's compliances that were praised divided by the number of total child compliance.

Conditional probabilities were calculated for all parent verbal and non-verbal behaviors to reveal the probability of child compliance following specific parent behaviors (Appendix F). The conditional probabilities were calculated in two ways. The first was the parent behavior based method. This was calculated by taking the number of intervals in which a child complied within 5 seconds of a parent behavior and dividing by the total number of times the specific parent behavior occurred. The second manner of calculating conditional probabilities was the child behavior based method, and the purpose of this calculation was to control for child compliance behavior base rates. This method was calculated by taking the number of intervals of child compliance occurring within 5 seconds of parent behaviors and dividing by the total number of times the child was compliant. Although conditional probabilities were calculated for all parent verbal and nonverbal behaviors, specific hypotheses were made only for the parent behaviors of direct command, indirect commands, and prompts, given that these have been more 
thoroughly supported in prior research (Eisenstadt et al., 1993; Schuhmann, Foote, Eyberg, Boggs, \& Algina, 1998; Stark et al., 1995). The conditional probabilities for the other behaviors were explored as a means of understanding the findings.

Training of four undergraduate coders, who were blind to study hypotheses, consisted of didactic teaching, provision of a training manual, and practice coding with videotapes. The practice videotapes were developed with parent actors directing children actors to perform $\mathrm{CF}$ treatments, the children refusing to comply with the parent's requests, and the parents conducting time outs. Prior to commencing on coding of actual study data, the coders had to achieve at least $80 \%$ total inter-rater agreement for three consecutive recordings of these staged parent-child interactions.

Inter-rater agreement was calculated for both the number of intervals where the coders both observed a response (OA: number of intervals both observers agreed the response occurred divided by the total number of intervals either observer said a response occurred) and for the number of intervals where they both did not observe a response (NA: number of intervals both observers agreed the response did not occur divided by the total number of intervals either observer did not code the response). Finally, total inter-rater agreement was also calculated (TA: total number of intervals both coders either agreed did or did not occur divided by total number of possible intervals). The coders coded 33\% (26 observations) of the same, randomly selected observations to evaluate inter-rater agreement. The coders were not aware of which observations were evaluated for reliability. Had either OA or NA dropped below $80 \%$ for 3 consecutive sessions, the plan was for the coders to stop coding and to re-train to criterion. The coders maintained a high rate of agreement and re-training was unnecessary. Table 1 provides the mean agreement and non-agreement reliability coefficients for the Observational Coding System. Of 
note is the finding that these agreement coefficients were low for certain parent behaviors, including direct commands, indirect commands, labeled praise, and unlabeled praise. It is thought that these coefficients were low because these parent behaviors were particularly difficult to differentiate.

Time out quiz (Appendix G). A time out quiz was created to objectively assess parent understanding of the time out based discipline strategy. This quiz consisted of 10 multiple choice questions including how to deliver appropriate commands, how to respond to a child's refusal to go to time out, and how to respond to time out escape behaviors. Parents completed this quiz two times during the course of their participation in this study, once at the start of the first intervention condition, and a second time at the start of the second intervention condition. A score of $100 \%$ was required for advancement to the intervention condition.

Exit interview (Appendix H \& I). Upon the completion of the study, the parents and child participated in an exit interview. The purpose of the exit interview was to query about parent and child perceptions of the time out based discipline strategy as compared to their typical child management strategies. Additionally, as part of this interview, the experimenter reviewed the graphed data of child compliance obtained from each condition of the study to help impress upon the parent the relation between time out and child compliance with parental requests.

\section{Procedure}

Recruitment and assessment. This study was approved by the Internal Review Board of West Virginia University. Families were recruited at the local CF clinic between the months of February and May. The CF physician or nurse approached families during their appointment to inquire whether they were willing to have a researcher meet with them for a few minutes to describe a research study. All families approached agreed to meet with the experimenter. During 
this initial meeting in the examination room, the experimenter screened the families to determine whether they met the inclusion criteria, described the study in greater detail and answered any questions that the parent and child had regarding study participation. All families approached had at least one child with CF between the ages of $2 \frac{1}{2}$ and 8 years, and two of the families had two children with $\mathrm{CF}$ who fell within the age range. Of the thirteen families approached, 8 families reported that their child had no current treatment-related behavior problems. Of those 8 families, 3 reported that their child had other behavior problems that they would be interested in addressing. For these families appropriate referrals were made. Of the 5 families who reported treatment-related behavior problems, one family reported that they were too busy to participate. One family, whose child had previously refused to swallow medications, agreed to participate. However, when contacted to arrange the baseline meeting, the child's mother reported that this difficulty had been addressed by using a specially designed cup to ease pill swallowing. Another family started the study, but had to withdraw while still in the baseline condition when their child developed Pseudomonas Aeuroginos and exhibited symptoms of depression including apathetic behavior and a reduction in her treatment refusal. The remaining two families participated in and completed the study.

The first home visit occurred 3 days prior to baseline data collection. At this visit, the experimenter obtained written parental informed consent, child assent, and had the parent complete the background information form, the CFPC, and the BASC-PRS-C. Families were informed that they would receive $\$ 60$ compensation upon the completion of each of four study conditions. After reviewing the specific treatment components on the CFPC endorsed by the family as problematic, the parent chose the treatment component and associated problem behaviors to be focused upon for improved compliance. During this meeting, the experimenter 
also conducted a structured interview to determine the function of the child's noncompliance to their parent's treatment requests, as identified on the CFPC.

At this initial meeting, the experimenter provided the families with an 8-mm video camera, seven 8-mm blank videotapes, a tripod, and typed instructions for how to use the camera (Appendix J). The experimenter taught the parent to use the camera and together the parent and the experimenter selected the best location to station the camera so as to be able to capture both the treatment commands and the entire time out procedures. The camera was left at this location throughout the duration of the study to habituate the family to the camera. The experimenter explained to the parents the importance of capturing the entire time out procedure on the video recording.

Design. A single-subject reversal design (i.e. ABAB) was employed for this study. The baseline (A) and reversal (second A) conditions consisted of the typical child management strategies that the parent used to enforce treatment-related commands. The time out procedure was employed for the two intervention conditions (B). Child compliance with parental treatment requests (direct and indirect commands and prompts) was the dependent variable of primary interest. Conditional probabilities of all parent verbal and nonverbal behaviors were also examined to determine how these variables related to child compliance. Parent's direct and indirect commands, as well as labeled praise and missed opportunities to praise compliance, were also monitored to determine whether the intervention relate to this variable. Finally, parent's ratings of their child's treatment-related behavior problems as assessed by the CFPC and parent's preference for parenting strategies were examined.

Baseline condition. Three days after the initial home visit, the experimenter telephoned the parents to instruct them to begin recording the target treatment component. This delay in 
onset of filming allowed for the parent and child to habituate to the camera. The parent videotaped the targeted treatment component each time it was conducted. Because both families lived a significant distance away from the experimenter, the families sent the videotapes of the treatment to the experimenter's office in a postage paid pre-addressed envelope provided by the experimenter. In all conditions, the tapes were coded according to the observational coding scheme to examine the stability of child compliance to parental treatment commands. The experimenter viewed each tape prior to the undergraduate research assistant coding so as to stay apprised of any issues that might arise during coding or as part of the intervention.

Parents were given feedback regarding their advancement to the next condition within 48 hours of receipt of the tape. Stability was determined through visual inspection of the graphed data. When data were continually unstable in any condition of the study, the experimenter consulted with committee chairs to determine the best course of action and to determine whether modifications were needed to obtain stability. The definition of stability for the baseline was at least 4 data points of stable or increasingly noncompliant child behavior. For the reversal and intervention condition, this definition was the same, but required only that the final 3 consecutive observations be stable or increasingly noncompliant. Once stability was achieved, the child advanced to the intervention condition. The experimenter updated the parents via telephone after each tape was coded whether they were ready to be advanced to the next condition or whether additional observations were required. When additional observations were required, the experimenter requested that the parent mail in tapes every 3 observations until stability had been obtained.

Intervention condition. Upon completion of the baseline condition, the experimenter met with the parent and requested that they complete the CFPC. Additional CFPC forms were 
provided to the parent and they were instructed to complete these forms when notified by the experimenter. During this visit, the experimenter provided a didactic session to explain the time out based discipline strategy to the parent (Appendix K). The time out based discipline strategy was derived from a popular and empirically-supported parenting program (Forehand \& Long, 2002). As part of this intervention, the parent learned to give a short and clear treatment-related command, to determine whether the child has complied with the command, to praise their child when compliance occurred, and to provide the child with a clear choice between complying with their original command or going to time out. Additional features of the time out based discipline strategy include how to place the child in an appropriate time out location, rules for when to end time out, and how to encourage future compliance (e.g., requiring the child to complete the original command at the end of the time out; requiring the child to comply with an additional, basic command at the end of the procedure). Ways to deal with time out refusal were also discussed, and parents were instructed to carry the child to the time out chair if he/she refused to go, and to use a back up time out room if the child refused to stay in the time out chair. Finally, the parent was instructed to use physical guidance after a time out time limit was reached. The time limit was decided upon after discussion with each family as to the maximum amount of time they could participate in a time out procedure while still maintaining their daily routine. Both parents reported that a 30 minute time limit would be the most time they could allow the time out procedure to continue while still maintaining their daily routine. Parents were instructed to use only the time out procedure for the targeted treatment behaviors, and not for general child noncompliance concerns. The experimenter instructed the parent to place the time out chair in a location where the procedure would be captured on the video camera. 
To ensure that the parent fully understood the time out based discipline strategy, the parent role played with the experimenter, with the parent initially playing the role of the child, and then with the experimenter playing the role of the child. The experimenter also provided the parent with handouts containing detailed flow-charts on assessing compliance and deciding when a child should go into time out (Appendix L). After the parent appeared to understand the procedure, the parent completed a "Time out quiz" (Appendix G) to evaluate parent understanding of time out based discipline strategy and to allow for clarification of any misunderstandings. Finally, the parent explained the time out based discipline strategy to his/her child in the presence of the experimenter. The experimenter helped to ensure that the child understood all aspects of the time out based discipline strategy, particularly the steps that the child needed to take to avoid time out. Finally, the parent and child practiced the time out based discipline strategy and the experimenter rewarded the child with stickers for participating in the role-play.

After the experimenter provided the parent feedback regarding their performance of the practice time out based discipline strategy, the parent and the child engaged in an analog to the treatment procedure where the parent practiced giving the child a number of direct commands and praising compliance. The purpose of this analog was to provide the parent with an opportunity to practice giving direct commands and labeled praise while the experimenter was present. This allowed the experimenter to provide feedback and answer any questions the parent and child may have had about the time out directive. Following the analog practice, all parent and child questions were addressed and parents were instructed to use the time out based discipline strategy when the child exhibited noncompliance for the targeted treatment only. The experimenter reminded the parents to capture all targeted treatments on videotape, encouraged 
them to call the experimenter should they have any questions, and provided them with additional blank videotapes and addressed stamped envelopes to mail the tapes to the experimenter. Parents mailed in the first tape after the first 3 observations.

Over the following 48-hour period, the experimenter checked the 3 observations for treatment integrity to determine the percentage of parent adherence to the time out based discipline strategy (see Appendix A) and the coders coded the observations to assess for stability. The definition of stability for the intervention condition was as follows: a period of at least 3 observations in which the parent was at least $75 \%$ adherent to the time out based discipline strategy ending with 3 consecutive observations in which there is no notable decrease in child compliance to parent treatment requests. If the parent averaged at least $75 \%$ adherence to the time out based discipline strategy over the combined period, and the data were stable, the experimenter telephoned the parent and instructed him/her to begin the reversal condition. The experimenter then requested that the parent complete the CFPC. In the case that stability had not been achieved in the first set of observations, families continued to mail in tapes and stability was assessed every three observations until it had been achieved, at which point the reversal condition began. An additional check of treatment integrity involved examining the frequency with which the parents employed the time out procedure following two events of child noncompliance to their parent's treatment requests. Of the time outs that Mary received, all of them followed two consecutive events of child noncompliance. This check was not performed for Janis because she did not go to time out during her participation in the study.

While Mrs. Doe's adherence to the time-out procedure never fell below 75\%, Mrs. Smith initially had difficulty following the based discipline strategy exactly and scored below $75 \%$ for her first set of observations. To address this concern, the experimenter telephoned Mrs. Smith 
and coached her on ways that she could improve her adherence to the time out based discipline strategy. Mrs. Smith was also encouraged to keep a copy of the time out based discipline strategy flow chart handy during treatment time. The coaching was effective, and the treatment integrity score for the following set of 3 observations was above $75 \%$.

Reversal condition. Once stability had been achieved in the first intervention condition, the experimenter telephoned the families and instructed the parent to refrain from using the time out based discipline strategy and to return to their typical child management strategies. The experimenter requested that the parent clarify to their child that they would no longer be using the time out based discipline strategy during the target medical treatment, but instead would use the child management strategy that they used before. During this telephone conversation, the experimenter reviewed with the parent the strategies that they previously employed, and provided them with some examples of these strategies (e.g., to threaten to turn off the television, or to lecture the child) obtained from baseline observations and the functional assessment. The experimenter explained to the parent that the goal of this condition was to return to their original strategies so that a good comparison could be made between those strategies and the time out based discipline strategy. Further, the experimenter also explained to the parent that the experimenter would view the tapes to make sure that time out based discipline strategy was not accidentally being implemented. Neither parent objected to the temporary return to their typical parenting strategy. After 3 observation periods, the experimenter requested that the families send in the first tape and reviewed them for any accidental use of the time out based discipline strategy. Such use of the time out based discipline strategy did not occur. This condition was continued until stability was achieved (i.e., at least 3 observations ending with at least 3 consecutive observations of stable or increasingly noncompliant child behavior). The families 
continued to mail in the tapes every three observations and the experimenter examined the graphed data until stability had been achieved.

Second intervention condition. During this final condition, parents were asked to use the time out based discipline strategy again. The experimenter contacted the parents and reviewed the time out based discipline strategy, had the parent complete the CFPC, and take the "Time out Based Discipline Strategy Quiz" over the phone to evaluate their knowledge regarding the proper implementation of the time out steps. Then, the parent was instructed to re-initiate the time out based discipline strategy. This final intervention condition was continued until stability had been achieved as evidenced by visual inspection of the graphed data (i.e., 3 observations ending with at least 3 consecutive observations of stable or increasingly noncompliant child behavior). After the initial 3 observations, the experimenter continued to review the tapes until discontinuation criteria had been met. Treatment integrity was monitored as in the first intervention condition, whereby tapes were reviewed after 3 observations and re-training sessions were held if parents fell below $75 \%$. During the second intervention condition, treatment integrity was above $75 \%$ for both participants. At the end of the final condition, the parents completed the CFPC and the BASC-PRS a final time, and parents and the child participated in the exit interview.

\section{Results}

\section{Aim One: Compliance with Treatment Requests}

Mary Smith. An examination of Mary's compliance results reveals that she exhibited the highest percentage of compliance to her mother's treatment requests in the two intervention conditions (see Figure 1, top panel). Mary's mean compliance scores for conditions ABAB were $37 \%, 65 \%, 49 \%$, and $66 \%$ respectively. Over the course of her participation in the study, Mary 
received three time outs: her first and second in the $4^{\text {th }}$ observation of the first intervention condition, and her third in the $8^{\text {th }}$ observation of the second intervention condition.

Parent-based conditional probabilities for direct command, indirect command, and prompt revealed similar patterns. Specifically, the likelihood of Mary's compliance behavior being contiguous to these parent behaviors was higher in the intervention conditions as compared to the baseline conditions (see Table 2). On average, Mary was 19 percentage points more likely to comply with her mother's direct commands, 9.5 percentage points more likely to comply with her mother's indirect commands, and 16.5 percentage points more likely to comply with her mother's prompts during the intervention conditions than the baseline or reversal conditions. The mean conditional probability rates for compliance for conditions $\mathrm{ABAB}$ following direct commands are $48 \%, 71 \%, 54 \%$, and $68 \%$ respectively. For indirect commands, the mean conditional probability rates for compliance for conditions $\mathrm{ABAB}$ are $37 \%, 37 \%, 46 \%$, and $65 \%$ respectively. Finally, the mean conditional probability rates for compliance following prompts for conditions $\mathrm{ABAB}$ are $7 \%, 28 \%, 14 \%$, and $26 \%$ respectively.

Using the child based calculations, Mary was 1.5 percentage points more likely to comply with her mother's direct commands, 4 percentage points more likely to comply with her mother's indirect commands, and 2.5 percentage points more likely to comply with her mother's prompts during the intervention conditions than during the baseline or reversal conditions (see Table 2). The child based calculations for mean conditional probability rates for conditions ABAB following direct commands are 76\%, 74\%, 59\%, and 58\% respectively. For compliance to indirect commands, the mean conditional probability rates for conditions $\mathrm{ABAB}$ using the child based calculations are $32 \%, 21 \%, 38 \%$, and $41 \%$ respectively. Finally, for the child based 
calculations for compliance to prompts, the mean conditional probability rates for conditions $\mathrm{ABAB}$ are $2 \%, 5 \%, 4 \%$, and $6 \%$ respectively.

Janis Doe. An examination of Janis' compliance rates indicates that during the initial baseline condition, Janis did not comply with any of her mother's treatment-related commands and prompts (see Figure 1, bottom panel). Following the time out based discipline strategy training, Janis' compliance rates improved to near total compliance. These high rates of compliance maintained throughout the remainder of her participation in the study, and no reversal was demonstrated. This trend is supported by the mean compliance scores for each condition. Specifically, her compliance scores for conditions ABAB were $0 \%, 96 \%, 94 \%, 98 \%$. Janis did not go to time out during her participation in the study. A follow-up conversation with Janis' CF physician revealed that following completion of her participation in the study Janis was able to swallow her enzyme medications.

Parent-based conditional probabilities for direct command and indirect command revealed that the average likelihood of Janis' compliance to these parent behaviors was higher in the intervention conditions than the baseline conditions (see Table 2). Janis was 55.5 percentage points more likely to comply with her mother's direct commands, and 14.5 percentage points more likely to comply with her mother's indirect commands when in the intervention conditions. It was not possible to calculate the probability of Janis' compliance following prompts as her mother did not issue any prompts following the initial baseline phase. The mean rates for direct commands in conditions $\mathrm{ABAB}$ are $0 \%, 98 \%, 87 \%$, and $100 \%$ respectively. The parent-based conditional probability rates for compliance to indirect commands in conditions $\mathrm{ABAB}$ are $0 \%$, $19 \%, 40 \%$, and $50 \%$, indicating an increased likelihood of compliance of 10 to 20 percentage points in each progressive phase. 
Using the child based calculations, Janis was 44 percentage points more likely to comply with her mother's direct commands, and 9 percentage points more likely to comply with her mother's indirect commands when in the intervention conditions (see Table 2). The child based conditional probability rates for compliance to direct commands in conditions $\mathrm{ABAB}$ are $0 \%$, $94 \%, 88 \%$, and $82 \%$. Her child based conditional probability means for indirect commands in conditions $\mathrm{ABAB}$ were $0 \%, 6 \%, 12 \%$, and $24 \%$.

Aim Two: Parent Behavior Change

Mary Smith. For Mrs. Smith, the mean percentage rates of direct commands relative to all commands given for conditions $\mathrm{ABAB}$ were $70 \%, 76 \%, 60 \%$, and $59 \%$, respectively (see Figure 2, top panel). An examination of Mrs. Smith's data reveals the mean frequencies for labeled praise relative to all praise in conditions $\mathrm{ABAB}$ were $28 \%, 9 \%, 2 \%$, and $41 \%$, respectively (Figure 2, top panel). In an examination of the percentage of compliant behavior praised relative to all compliant behavior exhibited, Mrs. Smith's mean rates of compliance behavior praised for conditions $\mathrm{ABAB}$ were $2 \%, 42 \%, 12 \%$, and $34 \%$ (Figure 2, top panel).

An examination of the average change of desirable parent behaviors revealed that the most change occurred between the first baseline and first intervention conditions (see Table 3). Mrs. Smith's mean desirable behavior percentages for conditions ABAB were as follows: 39\%, $54 \%, 35 \%$, and $38 \%$. Of the behaviors that contribute to this score, the labeled praise percentages were slightly higher during the intervention conditions, $2 \%$ and $6 \%$, than the baseline conditions, $1.7 \%$ and $1 \%$. Unlabeled praise was also somewhat higher in the intervention conditions, $15 \%$ and $6 \%$, than during the baseline conditions, $0.3 \%$ and $3 \%$. Direct commands appeared to decrease slightly throughout the ABAB conditions, 35\%, 35\%, 29\%, and 26\% respectively. 
Little change was noted in the physical positive scores, which were $2 \%, 2 \%, 2 \%$, and $0 \%$ for conditions $\mathrm{ABAB}$ respectively.

Mrs. Smith's rates of undesirable behaviors demonstrated a 2.3 percentage point decrease from the baseline conditions to the intervention conditions; however, an examination of the condition means reveals that there is overlap in the scores for each condition (see Table 3 ). Specifically, the baseline condition means, $18 \%$ and $22 \%$, are similar to the intervention means of $14 \%$ and $21.5 \%$. Similarly, little change was noted in any of the behaviors which contribute to the undesirable parent behavior scores. The mean scores in conditions ABAB for indirect commands were $17 \%, 13 \%, 20 \%$, and $19 \%$ respectively, and the scores for negative verbal attention were $1 \%, 1 \%, 1.5 \%$, and $0 \%$ respectively.

Although no specific predictions were made for the neutral behaviors (e.g., general verbal attention, physical prompt or guidance), it was noted that the average rates of neutral behaviors were 7.8 percentage points lower in the two intervention conditions, $32 \%$ and $38.5 \%$, when compared to the baseline conditions, $43 \%$ and $43 \%$ (see Table 3 ). The parent behavior that contributed most to this decline was Mrs. Smith's general verbal attention, which was slightly higher in the baseline conditions, $38 \%$ and $41 \%$ than in the intervention conditions, $30 \%$ and $37 \%$.

Janis Doe. For Mrs. Doe, the mean percentage rates of direct commands relative to all commands for conditions $\mathrm{ABAB}$ were $66 \%, 93 \%, 86 \%$, and $76 \%$ respectively (Figure 2 , bottom panel). The mean percentage rates of labeled praise relative to all praise that Mrs. Doe provided for conditions $\mathrm{ABAB}$ was $0 \%, 12 \%, 21 \%$, and 16\% respectively (Figure 2, bottom panel). Finally, Mrs. Doe's mean scores for compliance behaviors praised for conditions ABAB were $0 \%, 41 \%, 31 \%$, and $46 \%$ respectively. 
The rate of Mrs. Doe's desirable parent behaviors reflected the largest increase from baseline to the initial intervention conditions (see Table 3). The rates of desirable parent behaviors for conditions $\mathrm{ABAB}$ are $17 \%, 87 \%, 69 \%$, and $59 \%$, thus reflecting some overlap between the baseline and intervention condition rates. The frequency of direct commands, a behavior that contributes to the desirable parent behavior sum, for conditions $\mathrm{ABAB}$ were $17 \%$, $64 \%, 47 \%$ and 35\% respectively. Mrs. Doe's labeled praise scores for conditions ABAB were $0 \%, 7 \%, 2 \%$ and $6 \%$ respectively. The frequencies for unlabeled praise for conditions $\mathrm{ABAB}$ were $0 \%, 16 \%, 20 \%$ and 17 respectively. Mrs. Doe did not exhibit any physical positive behaviors during her participation. Independent of the study condition, there was significant variability in the frequency with which desirable parent behaviors were exhibited for Mrs. Doe. Specifically, when examining the frequency of behaviors that Mrs. Doe engaged in, direct commands comprised the most frequent behavior, followed by unlabeled praise, and finally, labeled praise.

Mrs. Doe's rate of undesirable behaviors, on average, declined 2.5 percentage points from baseline to intervention (see Table 3). An examination of the trends of the means for the sum of the undesirable behaviors reveals that the small difference between the intervention and baseline scores do not appear to be based upon a consistent pattern. Specifically, the rate of undesirable behaviors in conditions $\mathrm{ABAB}$ were $16 \%, 4 \%, 6 \%$, and 15\%, respectively. Mrs. Doe's frequency of negative verbal attention and indirect commands contributed to the undesirable behavior score. Although the frequency of Mrs. Doe's indirect commands generally increased throughout the study conditions, with scores of $8 \%, 4 \%, 6 \%$ and $15 \%$ for conditions $\mathrm{ABAB}$, she exhibited negative verbal attention in the baseline condition only, 8\%. Mrs. Doe's 
most frequent undesirable behavior was indirect commands, followed by negative verbal attention.

Mrs. Doe's neutral behaviors revealed an overall decrease in rate (see Table 3). Specifically, Mrs. Doe's mean rate of neutral behaviors for conditions ABAB were $67 \%, 9 \%$, $25 \%$, and $27 \%$. The behavior that contributed most to these scores was general verbal attention, which occurred at a mean rate of $59 \%$ and $25 \%$ in the first and reversal conditions, and $9 \%$ and $27 \%$ in the first and second intervention conditions.

Aim 3: Parent Perceptions of Problem Behavior and Time Out Based Discipline Strategy

Mary Smith. Mrs. Smith's CFPC problem intensity score indicated that Mary exhibited the most intense problems behaviors during the diet components of her treatment, followed by medication, and then CPT (Figure 3, top panel). Despite this reported pattern, CPT was the targeted treatment for this study as this was the component for which Mrs. Smith reported the highest number of problems for which she would like professional help (see problem item scores, Figure 4, top panel). The pattern of Mary's problem intensity ratings varied somewhat in the different conditions of the study. During the study, the problem intensity score for the targeted component, CPT, decreased from the pre-baseline score of 2.2 to a study completion score of 1.4. The problem intensity score for diet also declined from 3.1, at pre-baseline, to 2.5 at study completion. Mrs. Smith's problem intensity score for the medication component also declined from pre-baseline, 2.8 , to study completion, 1.2.

The problem item score for CPT declined throughout the study conditions, with a prebaseline score of 6 , and a completion score of 3 . The problem item score for diet also declined, from 4 at pre-baseline to 2 at study completion. Mrs. Smith's report of problem items for medication declined only slightly from a pre-baseline score of 3 to a study completion score of 2 . 
Mrs. Smith reported that she preferred the time out based discipline strategy over her typical child management strategy because it worked and it was organized. She also stated that she intended to continue to use time out to manage her daughter's treatment refusal behaviors. When asked what she did not like about the time out based discipline strategy, Mrs. Smith reported that she hated to punish her daughter, especially when the misbehavior surrounded anything related to her illness. When asked what she liked and did not like about her previous child management strategy, Mrs. Smith reported that nagging and yelling at her daughter was easy as it "came natural to me," although she did not like engaging in those behaviors. Finally, Mrs. Smith reported that she did not use the time out based discipline strategy during the course of the study to manage Mary's nontargeted treatment-related behavior problems. When asked about her perceptions of the time out based discipline strategy, Mary reported that she preferred her mother's previous discipline strategy, because she did not like time out. She did not elaborate on any details of her preference.

Janis Doe. Mrs. Doe's CFPC problem intensity scores indicated that Janis exhibited the most intense behavior problems during the medication components of her treatment, followed by diet, and then CPT (see Figure 3, bottom panel). This pattern of problem intensity ratings was consistent in each condition of the study. During the study, the problem intensity score for the targeted component, medication, decreased from the pre-baseline score of 3.2 to a study completion score of 1.3 . The problem intensity score for diet also declined from 2.5 , at prebaseline, to 1.3 at study completion. Mrs. Doe's problem intensity score for CPT did not decline; rather it slightly increased from pre-baseline, .9 , to study completion, 1.

Similar to the problem intensity scores, Mrs. Doe initially rated medication and diet as treatment components with which she wanted the most help, as seen on her problem item scores 
(see Figure 4, bottom panel). According to Mrs. Doe's problem item scores, she was not in need of any help for CPT related refusal behaviors. Mrs. Doe's problem item scores for medication, the targeted treatment component, declined steadily from her pre-baseline scores of 4 , to the completion scores of 1 . The problem item scores for diet also followed a similar pattern, with a pre-baseline score of 4 , and a study completion score of 1 .

The parent exit interview for Mrs. Doe revealed that she preferred the time out based discipline strategy to her typical child management strategies for management of Janis' medication refusal behaviors. Specifically, she reported that she preferred the consistency that the time out based discipline strategy provided for her own behavior. She did not report any specific concerns regarding her previous child management strategy, other than the fact that it was ineffective. Mrs. Doe also reported that she intended to utilize the time out based discipline strategy upon study completion. Finally, Mrs. Doe reported that she did not use the time out based discipline strategy strategies to manage Janis' general behavior problems during the course of the study. Unfortunately, it was not possible to obtain Janis' perception of the time out based discipline strategy as she refused to respond to the researcher's questions.

\section{Behavioral Assessment System for Children - Parent Rating Scale for Children (BASC-PRS-C)}

\section{Findings}

Mary Smith. On the BASC-PRS-C, Mrs. Smith's baseline and study completion response sets suggested that she was responding in a valid and forthright manner (see Table 4). On the baseline administration, Mrs. Smith's responses indicated that Mary was in the "At-Risk" range for the following constructs: Hyperactivity, Depression, Somatization, and Attention Problems. An examination of Mary's composite scores revealed that at baseline, Mrs. Smith's responses placed Mary's behaviors in the at-risk category for Externalizing Problems, Internalizing 
Problems, and in the Behavioral Symptoms Index. Behaviors in the "At-Risk" range may not be severe enough to require formal treatment but could represent a potential problem likely to develop, and therefore warrant careful monitoring. None of Mrs. Smith's ratings of Mary's behaviors fell into the clinically significant range for any of the adaptive or clinical scales.

Mrs. Smith's ratings of Mary's behavior at study completion revealed only one elevation. Specifically, Mrs. Smith's report indicated that Mary's behaviors were in the "At-Risk" range for the Anxiety scale. Similar to her baseline scores, none of the study completions ratings of Mary's behaviors fell into the clinically significant range. Therefore, Mrs. Smith's perceptions of Mary's behavior changed from baseline to study completion to reflect fewer behavior problems.

Janis. On the BASC-PRS-C, Mrs. Doe's baseline and study completion response sets suggested that she was responding in a valid and forthright manner (see Table 4). During both baseline and study completion administrations of the BASC, Mrs. Doe's responses indicated that Janis was in the "At-Risk" range for only the Adaptability construct. None of Mrs. Doe's ratings of Janis' behaviors fell into the clinically significant range during either administration.

\section{Discussion}

The current study was conducted to examine the effectiveness of a time out based discipline strategy in increasing children's compliance with their parent's CF treatment requests. There were four main findings in the current study. First, when examining children's compliance to their parent's treatment requests, it appears that the time out based discipline strategy was more effective in increasing child treatment compliance than parent's typical child management strategies, at least for one participant. Additionally, child compliance was generally more likely to occur in the presence of commands and praise during the intervention conditions as compared to the baseline conditions. Second, moderate changes were noted in parent behavior as a function 
of study condition. Specifically, parents were more likely to praise compliant behaviors during the intervention as compared to the baseline conditions. Third, parent perceptions of their child's treatment-related behavior problems indicated that they desired less professional help for these problems, and that they perceived these problems to be less intense, at the completion of the study as compared to at the start of the study. Fourth, parents reported that they preferred the time out based discipline strategy over their typical child management strategy. When interpreting these findings, several methodological limitations should be considered. The findings and their clinical implications will be discussed below. In addition, limitations of this study and future directions will be detailed.

\section{Main Findings}

\section{Overall Effectiveness of the Time Out Intervention}

It was expected that the time out based discipline strategy would result in greater child compliance to parent treatment requests than parent typical child management strategies. Visual inspection of the observational assessment data and conditional probabilities provides some support for this hypothesis. It is important to note that the time out based discipline strategy was based upon the Forehand and McMahon model that included multiple components such as praising compliance, removal of attention for noncompliance, and extinguishing treatment avoidance by requiring the child to comply with the treatment request following the time out. Differential reinforcement of alternative behaviors (DRA) may be the mechanism which best accounts for the parent and child behavior change, primarily for one participant. DRA involves providing reinforcement for a behavior other than the specific problem behavior and removing reinforcement of the problem behavior (Vollmer \& Iwata, 1992). In the current study, the attention and praise likely served to positively reinforce compliance. Additionally, by ignoring 
noncompliant behaviors, either through intensive ignoring in a time out procedure, or by not attending to noncompliant behaviors, the parents removed the positive reinforcement (attention) which previously had been provided to their child's noncompliant behaviors. Because the time out procedure did not end until the child had complied with the parent's original treatment request, the negative reinforcement the child received by avoiding the treatment was decreased.

When the participants are considered individually, the efficacy of the intervention is challenged by the lack of reversal in Janis' data, suggesting that her noncompliance was not under experimental control and that ultimately the intervention was not removed from her during the reversal period. It might be that the primary functions of both Mary's and Janis' noncompliance behaviors were to avoid treatment, although the process by which Janis developed her avoidance behaviors differed from Mary’s. Mary's noncompliance behaviors likely developed primarily through operant conditioning in response to both negative reinforcement, in that noncompliance allowed her to avoid an unpleasant event, and positive reinforcement, in that her noncompliance resulted in her mother providing her with attention and stimulation. Thus, the time out based discipline strategy that reversed these contingencies would be effective. Some support for this explanation is provided by Mary's general return to noncompliance when the original contingencies were reintroduced in the reversal phase.

The development of Janis' noncompliance to pill swallowing might be better explained by Mowrer's two-factor theory, which suggests that the development and maintenance of avoidance behaviors occurs through a combination of classical and operant conditioning (Kymissis \& Poulson, 1990; Mowrer, 1939). In other words, Janis’ initial experience with gagging and vomiting when attempting to swallow the pill resulted in the pill swallowing assuming negative associations via classical conditioning. Subsequently, her avoidance of pill 
swallowing could have been maintained via negative reinforcement (i.e., avoiding gagging, vomiting, and choking). Thus, an intervention that exposes Janis to pill swallowing without gagging and vomiting appears to have extinguished the classically conditioned avoidance response when presented with a request to swallow pills. Additionally, once Janis began swallowing pills, her avoidance was no longer maintained via negative reinforcement. However, removing the time out based discipline strategy did not reintroduce this classically conditioned response and thus a return to baseline levels of noncompliance would not be expected. Additionally, because Mrs. Doe continued to praise Janis' behavior at high rates, the positive reinforcement component of the time out treatment package was never truly removed during the reversal phase.

Taking into consideration the general compliance findings as well as the conditional probability findings, the results suggest that the time out based discipline strategy resulted in increases in child compliance and decreases in noncompliance to parent's treatment requests, primarily for Mary. The mechanism that served to produce this change appears to be that of a DRA model in which compliance behaviors were strengthened through positive reinforcement and noncompliance was extinguished through ignoring. In Janis' case, the intervention also served to decrease her pill swallowing noncompliance by not allowing her to obtain negative reinforcement (avoidance) and extinguishing the connection between pills and negative physiological reactions. However, because Janis' noncompliance did not reverse, research is needed to replicate the findings and provide additional support for the effectiveness of the time out based discipline strategy in increasing children's compliance to parent treatment requests. Parent Behavior Change 
It was expected that during the intervention condition the parents would exhibit behavior change in several key areas. Specifically, consistent with training, increases were anticipated in direct commands, labeled praise, and compliant behavior praised. Of these three parent behaviors, only praising of compliant behavior demonstrated the expected pattern of results for both participants, with parents being more likely to praise compliant behavior in the intervention conditions than in the baseline conditions. Direct commands started out at an elevated rate for both parents. This finding may be indicative of a possible ceiling effect. In other words, because the parents in this study were already demonstrating high rates of direct commands, it becomes difficult to detect the effect of the intervention upon this parent behavior. It is important to note that these proportions of direct to indirect commands are similar to those found in parents of typically behaving children (Eyberg, Bessmer, Newcomb, Edwards, \& Robinson, 1994).

When examining the parent behaviors as they relate to increased child compliance, several findings suggest that praising of compliant behavior was the parent behavior most responsible for increased child compliance. This finding is not surprising given the consistent correlation between praise and compliance (Eisenstadt et al., 1993). Interestingly, of the changes in rates of desirable parent behaviors, the overall changes in the frequency rates of praising, independent of compliant behaviors, demonstrated only moderate gains. Therefore, it appears that the specific parent behavior relating to increases in child compliant behavior is best understood in light of the parent behavior change of praising compliance and not just increasing praise per say. This hypothesis is further supported by the finding for the parent-based conditional probabilities for praise. Finally, changes in the parent behavior of general verbal commands were noted such that parents were less likely to exhibit these behaviors during the intervention as compared to the baseline conditions. These changes reflected a general decrease 
in the amount of time that parents devoted to the completing the treatment. With children complying with their parents treatment requests the treatment were completed more quickly and parents had fewer opportunities to display general verbal behavior.

\section{Parent Perceptions of Child Treatment Refusal Behaviors}

On the CFPC, parents reported moderate decreases in treatment-related behavior problem intensity and in the total number of problems with which they would like professional help. This occurred not just for the target treatment, but also for all treatments assessed by the CFPC for which the parents initially reported wanting professional help. This pattern of results provides some support for a generalization effect whereby the participants, upon becoming more compliant with one area of treatment, also become increasingly compliant with other areas. This type of generalization process has been shown in other research. For example, parent training has been shown to generalize from increased child compliance in the clinic to other settings, including home and school (Herschell, Calzada, Eyberg, \& McNeil, 2002). The explanation is that once a specific behavior has been strengthened in the presence of a situation or stimulus, then that behavior is more likely to occur in the presence of similar situations or stimuli. Generalization is less likely to occur for more formal interventions, such as token economies, in which the intervention is less easily adapted to other treatments or settings (Rapoff et al., 1984).

In the current study, generalization could be explained by changes in both the parent and child behaviors. For example, after finding that their child was more compliant to the targeted treatment when they employed direct commands and praised compliance, the parents may be more likely to engage in these behaviors when they conducted other CF treatments. Additionally, after repeatedly receiving social reinforcement for increasing compliance to a parent's treatment requests for one CF treatment component, the children may be more likely to comply with their 
parent's other CF treatment requests. Because compliance in only one area of treatment was captured on videotape, it is not possible to determine whether actual changes in parent behavior and child compliance were occurring during other treatment components or whether the changes reflected a shift in parent perceptions. Parents were instructed to employ the time out based discipline strategy for the targeted treatment component alone, and both parents reported that they did not employ the time out based discipline strategies for any problem behaviors other than those occurring during the target treatment.

An additional explanation for the reductions in parents' reported desire for professional help is that parents might have increased in their perceived self-efficacy in managing their child's treatment refusal behaviors. Perceived self-efficacy is an individual's perception of their ability to exercise control over factors that significantly impact their life (Bandura, 1994). Thus, parents' self-efficacy with managing their child's noncompliance in one component of CF treatment might have generalized to other components of CF treatment. Research has suggested that perceived self-efficacy plays a central role in areas such as predicting academic achievement and health behaviors such as healthy diet (Pajares \& Schunk, 2001; Parcel, Simons-Morton, O'Hara, Baranowski, \& Wilson, 1989). Given that these results reflect parent opinion, response bias and reactivity cannot be ruled out.

\section{Parent and Child Perceptions of the Intervention}

Parents reported preferring the time out based discipline strategy to their typical child management strategies. Both parents indicated that they appreciated the structured and organized nature of the time out based discipline strategy and felt that it was more effective than their typical child management methods. In interpreting this finding, it is important to consider that both parents were highly motivated to change their child's treatment refusal behaviors. On 
multiple occasions, both parents reported to the researcher that they had feelings of anxiety and distress with regard to their child's noncompliance with their treatment requests. Research suggests that parents of children with chronic illnesses generally view their child's behavior as more excusable than that of physically healthy children (Walker et al., 1995). This perception, coupled with a desire to maintain a positive parent-child relationship with a terminally ill child, could make it difficult for parents of children with CF to discipline their child. It is possible that the time out based discipline strategy allowed the parents to reduce child noncompliance while also maintaining a positive parent-child relationship, and therefore provided parents with a sense of self-efficacy in managing their child's treatment-related noncompliance. Given that other research has demonstrated correlations between adherence to medical regimens and positive parent-child relationships (Miller-Johnson et al., 1994), uncovering ways for parents to effectively discipline their chronically ill child while maintaining positive parent-child relationships may be important in improving adherence.

\section{Methodological Limitations}

\section{Participants}

In interpreting the study findings and considering the generalizability of these data, it is important to bear in mind several factors. First, both participants were Caucasian females from intact, rural families, roughly the same age and did not have clinically significant behavior problems according to behavior rating scales. Additionally, both parents presented with unique demographic factors which may have influenced the rapidity with which they mastered the intervention. Specifically, Mrs. Smith reported having participated in behavioral oriented training program approximately 5 years prior to encourage adaptive behavior in her son who had been diagnosed with autism. Mrs. Doe worked as an elementary school teacher, and reported that 
she had been working with a class of special needs children for approximately one year. For both parents, the training that they received for their work with special needs children may have resulted in their ability to master and implement the intervention skills more quickly than individuals who had not had such training. Although this specialized training may have made it easier for the parents to master the intervention skills, given that both parents had been trained in the skills for significant period of time prior to the start of the study, it is unlikely that the increases in compliance could be attributed to these previously learned skills. These findings may not apply to children with clinically significant behavior problems or parents in different situations.

\section{Experimental Design}

A limitation of this study was that Janis' compliance data did not return to baseline rates of noncompliance in the reversal condition; thus, experimental control of her noncompliance was never established. This lack of reversal could be due to a carryover effect. A carryover effect is an effect that "carries over" from one experimental condition to the next. Such an effect makes it difficult to draw strong conclusions regarding the impact of the intervention upon compliance behavior. Several explanations exist for why carryover effects occur. One explanation is the extinction of Janis' pills swallowing avoidance extinguished her conditioned fear of pills. In other words, if Janis' avoidance of pill swallowing was the factor maintaining her pill refusal, then once these fearful behaviors had been extinguished and the avoidance no longer received negative reinforcements, then there were no longer any other factors maintaining pill refusal. An additional explanation of this carryover effect was that the intervention was never truly removed for Janis, in that her mother continued to praise Janis' compliant behavior at a high rate, thus continuing to employ an important component of the time out based discipline strategy. To avoid 
carryover effects in single-subject research, researchers suggest counterbalancing the order of the conditions and minimizing the number of observations conducted for each condition (Barlow \& Hayes, 1979).

Another limitation of the research is the difficulty in interpreting the CFPC results. Specifically, since the research investigated only a single treatment component through observational assessment, it was not possible to determine whether the parent-reported improvements on the CFPC reflected increases in child compliance to nontargeted treatment components, reactivity, or response biases. In the future, a multiple baseline across treatment component design might help determine whether the intervention resulted in actual behavior change for nontargeted treatments.

An additional measurement limitation is the lack of observational data assessing parent ignoring or extinction behaviors. Although the current observational coding system allows for an evaluation of changes in parents' positive reinforcement of compliance behaviors, the same cannot be said for extinction behaviors or ignoring of noncompliance as these behaviors were not directly assessed. Whereas conclusions might be draw from the data set with regard to the connection between praise and behavior change, the current behavioral observation tool does not allow for such conclusions to be drawn between extinction and behavior change. A final limitation of the current work is the small sample size.

\section{Clinical Implications}

The general findings of the current research study have several potential clinical implications. First, it is important to consider that child behavior improved with relatively little instruction and parent training. Parents in the current study received a single, 2 hour training session followed by 1 to 2 brief telephone calls to discuss treatment integrity. Other research 
employing behavioral methods have included more time intensive therapy (Stark et al., 2003). Brief cost-effective therapies are especially well suited for families in rural areas where they must drive long distances to attend weekly parent training sessions. Additionally a brief therapy may also be desirable for families with a chronically ill child because of the time demanded by medical treatments and physician appointments.

A second implication of this study involves the use of time out based discipline strategy for children's avoidance based behaviors. Although previous researchers have employed time out based discipline strategies for certain aspects of medical noncompliance (Babbitt et al., 1991), such research was implemented in the lab by researchers rather than parents, and the researchers did not conduct a functional assessment. The central mechanism of time out based discipline strategies is the removal of attention or extinction of reinforcement for noncompliant behaviors (Forehand \& Long, 2002; Forehand \& McMahon, 1981). As such, it has been suggested that unless a child's behavior functioned for attention, time out procedures would not be effective. For example, if a child's behavior was functioning for avoidance, time out would allow further avoidance (Handen et al., 1992; Stark et al., 1993). The current research provides preliminary evidence to suggest that a time out based discipline strategy that includes positive reinforcement for compliance and removal of reinforcement for noncompliance behaviors might decrease avoidance-based behavior.

\section{Directions for Future Research}

This study provides initial support for using a time out based discipline strategy to address noncompliance to parent's treatment requests in children with CF. Future research is needed to confirm and broaden the current findings. Such research should be conducted with children of differing ages and genders, and in families with different demographic backgrounds. 
Additionally, a limitation of the current study was the small sample size. Future research investigating the efficacy of time out should include at least three participants. Finally, because Janis' data did not demonstrate a reversal, it is important to replicate findings in regard to Mary. Additionally, more research should be done to evaluate the benefits of a time out versus an intervention focused solely upon exposure to extinguish a classically conditioned avoidance response. Such research could determine whether the time out based discipline strategy has any advantages over well established exposure protocols.

Other directions for future research include dismantling the current time out based discipline strategy to determine which components of the procedure are the most effective at increasing child compliance to parent treatment request. Such research could allow for a careful investigation of the individual influence of specific parent behaviors, such as ignoring and contingent praise, upon child compliance. Additionally to explore the generalization of the intervention, future research should employ a multiple baseline across behaviors design whereby the time out based discipline strategy would be initially employed for a single treatment component, and then extended to include others. This would enable researchers to determine whether the decreases in problem intensity reported in treatments other than the targeted treatment reflect a shift in parent reporting alone or in child behavior change as well. Given the paucity of research assessing child noncompliance with medical requests, an investigation of the prevalence rates of child noncompliance is also warranted. In the current research, 5 of the 13 families approached reported that their child exhibited significant issues with medical noncompliance.

Another direction of future research would be to investigate parent reports of emotional distress as they relate to child discipline for medical noncompliance. Parents of children with CF, 
or other terminal chronic illnesses, are placed in the difficult position of requiring their child to participate in treatments, which are often laborious and painful. Understanding how this position impacts parents will allow for clinicians and researchers to address these important emotional issues with parents and to tailor interventions which directly confront these concerns.

It should also be noted that there was considerable fluctuation in child and parent behavior within study conditions. Additional research that identifies other environmental contingencies controlling this behavior is warranted. Although a functional assessment was conducted, it is possible that other antecedents and consequences might have been missed that are better predictors of child compliance. In addition, identifying the contingencies that influence parent behavior might shed additional light on parent behavior, child behavior, and the interaction of the parent and child.

\section{Conclusion and Summary}

This study provided an initial evaluation of the use of a time out based discipline strategy to manage treatment-related noncompliant behaviors in to children with CF. Findings from one participant suggest that the time out based discipline strategy may be a promising intervention to decrease noncompliant behaviors, in particular when the function of the noncompliant behavior is to avoid the treatment. There is moderate support for the conclusion that contingent praise for compliant behavior is instrumental in child behavior change. The findings indicate that the mechanism of differential reinforcement of alternative behavior may have been responsible for Mary's behavior change. Both parents reported preferring the time out based discipline strategy over their previous parenting strategies. Additionally, parents reported that the effects of the based discipline strategy generalized to non-targeted CF treatments in that they perceived fewer behavior problems and desired less professional help in these areas. Despite a number of 


\section{Evaluation of Time Out 66}

limitations, these findings provide preliminary support for the efficacy of a time out based discipline strategy to manage treatment noncompliance. 


\section{References}

American Academy of Pediatrics. (1998). Guidance for Effective Discipline (Vol. 101, pp. 723728).

Babbitt, R. L., Parrish, J. M., Brierley, P. E., \& Kohr, M. A. (1991). Teaching developmentally disabled children with chronic illness to swallow prescribed capsules. Journal of Developmental Behavioral Pediatrics, 12(4), 229-235.

Bandura, A. (Ed.). (1994). Self-efficacy. (Vol. 4). New York: Academic Press.

Barlow, D. H., \& Hayes, S. C. (1979). Alternating treatment design: One strategy for comparing the effects of two treatments in a single subject. Journal of Applied Behavior Analysis, $12(2), 199-210$.

Berg, J. S., Dischler, J., Wagner, D. J., Raia, J., \& Palmer-Shevlin, N. (1993). Medical compliance: A health care problem. Annals of Pharmacotherapy, 27 (Suppl.), 2-21.

Cadman, D., Boyle, M., Szatmari, P., \& Offord, D. (1987). Chronic illness disability and mental and social well-being: Findings of the Ontario Child Health Study. Pediatrics, 79, 805813.

Crist, W., McDonnell, P., Beck, M., Gillespie, C. T., Barrett, P., \& Mathews, J. (1994). Behavior at mealtimes and nutritional intake in the young child with cystic fibrosis. Journal of Development and Behavioral Pediatrics, 15, 157-161.

Dix, T., Ruble, D. N., Grusec, J. E., \& Nixon, S. (1986). Social cognition in parents: inferential and affective reactions to children of three age levels. Child Development, 57(4), 879894.

Doyle, A., Ostrander, R., Skare, S., Crosby, R. D., \& August, G. (1997). Convergent and criterion-related validity of the Behavior Assessment System for Children - Parent Rating Scales. Journal of Clinical Child Psychology, 26, 276-284. 
Drotar, D., \& Ievers, C. E. (1994). Preliminary report: Age differences in parent and child responsibilities for management of cystic fibrosis and insulin-dependent diabetes mellitus. Journal of Development and Behavioral Pediatrics, 15, 367-374.

Eisenstadt, T. H., Eyberg, S. M., McNeil, C. B., Newcomb, K., \& Funderberk, B. (1993). Parentchild interaction therapy with behavior problem children: Relative effectiveness of two stages of overall treatment outcome. Journal of Clinical Child Psychology, 22, $42-51$.

Eiser, C., Zoritch, B., Hiller, J., Havermans, T., \& Billig, S. (1995). Routine stresses in caring for a child with cystic fibrosis. Journal of Psychosomatic Research, 39(5), 641-646.

Eyberg, S. M., Bessmer, J., Newcomb, K., Edwards, D., \& Robinson, E. (1994). Dyadic ParentChild Interaction Coding System-II: A Manual., Social and Behavioral Sciences Documents.

Fitzsimmons, S. C. (1993). The changing epidemiology of cystic fibrosis. Journal of Pediatrics, 122(1-9).

Forehand, R. L., \& Long, N. (2002). Parenting the Strong-Willed Child. NY: McGraw-Hill.

Forehand, R. L., \& McMahon, R. J. (1981). Helping the noncompliant child. New York: Guilford.

Forgatch, M. S. (1991). The clinical science vortex: Developing a theory for antisocial behavior. In K. H. Rubin (Ed.), The development and treatment of childhood aggression. Hillsdale, NJ: Erlbaum.

Foster, C. L., Bryon, M., \& Eiser, C. (1998). Correlates of well-being in mothers of children and adolescents with cystic fibrosis. Child: Care, Health and Development, 24(1), 41-56. 
Gordis, L., Markowitz, M., \& Lilienfeld, A. M. (1969). Why patients don't follow medical advice: a study of children on long-term antistreptococcal prophylaxis. Journal of Pediatrics, 75(6), 957-968.

Greenan-Fowler, E., Powell, C., \& Varni, J. W. (1987). Behavioral treatment of adherence to therapeutic exercise by children with hemophilia. Archieves of Physical Medicine and Rehabilitation, 68(12), 846-849.

Gretarsson, S. J., \& Gelfand, D. M. (1988). Mothers' attributions regarding their children's social behavior and personality characteristics. Developmental Psychology, 24(2), 264-269.

Hagopian, L. P., \& Thompson, R. H. (1999). Reinforcement of compliance with respiratory treatment in a child with cystic fibrosis. Journal of Applied Behavior Analysis, 32(2), 233-236.

Hamilton, S. B., \& MacQuiddy, S. L. (1984). Self-administered behavioral parent training: Anhancement of treatment efficacy using a time-out signal seat. Journal of Clinical Child Psychology, 13, 61-69.

Handen, B. L., Parrish, J. M., McClung, T. J., Kerwin, M. E., \& Evans, L. D. (1992). Using guided compliance versus time out to promote child compliance: A preliminary comparative analysis in an analogue context. Research in Developmental Disabilities, 13, 157-170.

Haring, T. G., \& Kennedy, C. H. (1990). Contextual control of problem behavior in students with severe disabilities. Journal of Applied Behavior Analysis, 23, 235-243.

Haynes, R. B. (1979). Introduction. In D. L. Sackett (Ed.), Compliance with Health Care (pp. 17). Baltimore: Johns Hopkins. 
Hembree-Kigin, T. L., \& McNeil, C. B. (1995). Parent-Child Interaction Therapy. New York: Plenum.

Herschell, A. D., Calzada, E. J., Eyberg, S. M., \& McNeil, C. B. (2002). Parent-child interaction therapy: New Directions in research. Cognitive and Behavioral Pratice, 9(1), 9-15.

Ievers, C. E., Brown, R. T., Drotar, D., Caplan, D., Pishevar, B. S., \& Lambert, R. G. (1999). Knowledge of physician prescriptions and adherence to treatment among children with cystic fibrosis and their mothers. Developmental and Behavioral Pediatrics, 20, 335-343.

Ievers, C. E., Drotar, D., Dahms, W. T., Doershuk, C. F., \& Stern, R. C. (1994). Maternal childrearing behavior in three groups: Cystic fibrosis, insulin-dependent diabetes mellitus, and healthy children. Journal of Pediatric Psychology, 19(6), 681-687.

Jaffe, A., \& Bush, A. (2001). Cystic Fibrosis: Review of the decade. Monaldo Archives of Chest Disease, 56(3), 240-247.

Konstan, M. W., Byard, P. J., Hoppel, C. L., \& Davis, P. B. (1995). Effect of high-dose ibuprofen in patients with cystic fibrosis. New England Journal of Medicine, 332(13), 848-854.

Koocher, G. P., McGrath, M. L., \& Gudas, L. J. (1990). Typologies of nonadherence in cystic fibrosis. Journal of Development and Behavioral Pediatrics, 11(6), 353-358.

Kymissis, E., \& Poulson, C. L. (1990). The history of imitation in learning theory: The language acquistion process. Journal of the Experimental Analysis of Behavior, 54(2), 113-127.

Lemanek, K. L., Kamps, J., \& Chung, N. B. (2001). Empirically supported treatments in pediatric psychology: Regimen adherence. Journal of Pediatric Psychology, 26(5), 253275. 
Mace, F. C., \& Heller, M. (1990). A comparison of exclusion time-out and contingent observation for reducing severe disruptive behavior in a 7-year-old boy. Child and Family Behavior Therapy, 12, 57-68.

Matthews, L. W., \& Drotar, D. (1984). Cystic fibrosis--a challenging long-term chronic disease. Pediatric Clinics of North America, 31(1), 133-152.

Merenda, P. F. (1996). BASC: Behavior Assessment System for Children. Measurement and Evaluation in Counseling and Development, 28, 229-232.

Miller-Johnson, S., Emery, R. E., Marvin, R. S., Clarke, W., Lovinger, R., \& Marti, M. (1994). Parent-child relationships and the management of insulin-dependent diabetes mellitus. Journal of Consulting and Clinical Psychology, 62(3), 603-610.

Mowrer, O. H. (1939). A stimulus-response analysis of anxiety and its role as a reinforcement agent. Psychology Review, 46, 553-556.

O'Neil, R. E., Horner, R. H., Albin, R. W., Storey, K., \& Sprague, J. R. (1990). Functional Analysis of Problem Behavior. Sycamore; IL: Sycamore Publishing Company.

Pajares, F., \& Schunk, D. H. (2001). Self-beliefs and school success: Self-Efficacy, self-concept, and school Achievement. In S. Rayner (Ed.), Perception (pp. 239-266). London: Ablex Publishing.

Parcel, G. S., Simons-Morton, B., O'Hara, N. M., Baranowski, T., \& Wilson, B. (1989). School promotion of healthful diet and physical activity: Impact on learning outcomes and selfreported behavior. Health Education Quarterly, 16(181-199).

Passero, M. A., Remor, B., \& Salomon, J. (1981). Patient-reported compliance with cystic fibrosis therapy. Clinical Pediatrics, 20, 264-268. 
Patterson, J. M., Budd, J., Goetz, D., \& Warwick, W. J. (1993). Family correlates of a 10-year pulmonary health trend in cystic fibrosis. Pediatrics, 91(2), 383-389.

Patterson, J. M., McCubbin, H. I., \& Warwick, W. J. (1990). The impact of family functioning on health changes in children with cystic fibrosis. Social Sciences in Medicine, 31(2), 159-164.

Pelco, L. E., Kissel, R. C., Parrish, J. M., \& Miltenberger, R. G. (1987). Behavioral management of oral medication administration difficulties among children: a review of literature with case illustrations. Journal of Development and Behavioral Pediatrics, 8, 90-96.

Powers, S. W., Patton, S. R., Byars, K. C., Mitchell, M. J., Jelalian, E., Mulvihill, M., Melbourne, F., Hovell, M., \& Stark, L. J. (2002). Caloric intake and eating behavior in infancts and toddlers with cystic fibrosis. Pediatrics, 109(5), 1-10.

Prasad, S. A., \& Cerny, F. J. (2002). Factors that influence adherence to exercise and their effectiveness: Application to cystic fibrosis. Pediatric Pulmonology, 34(1), 66-72.

Quittner, A. L., DiGirolamo, A. M., Jacobsen, J., \& Eigen, H. (1991). A contextual model of parenting problems and outcomes for newly diagnosed families. Pediatric Pulmonology, $10,310$.

Quittner, A. L., Drotar, D., Ievers-Landis, C. E., Seidner, D., \& Jacobsen, J. (2000). Adherence to medical treatments in adolescents with Cystic Fibrosis: The development and evaluation of family-based interventions. In D. Drotar (Ed.), Promoting Adherence to Medical Treatment in Chronic Childhood Illness. Mahwah, NJ: Larwrence Erlbaum Associates.

Ramsey, B., Farrell, P., \& Pencharz, P. (1992). Nutritional assessment and management in cystic fibrosis: Consensus conference. American Journal of Clinical Nutrition, 55, 108-116. 
Rapoff, M. A. (1999). Adherence to Pediatric Medical Regimens. New York: Kluwer Academic/Plenum Publishers.

Rapoff, M. A., \& Barnard, M. U. (1991). Compliance with pediatric medical regimens. In B. Spilker (Ed.), Patient compliance in medical practice and clinical trials (pp. 73-98). New York: Raven Press.

Rapoff, M. A., Lindsley, C. B., Edwards, D., \& Christophersen, E. R. (1984). Improving compliance with medical regimens: Case study with juvenile rheumatoid arthritis. Archives of Physical Medicine and Rehabilitation, 65(5), 267-269.

Rapoff, M. A., Purviance, M. R., \& Lindsley, C. B. (1988). Educational and behavioral strategies for improving medication compliance in juvenile rheumatoid arthritis. Archives of Physical Medicine and Rehabilitation, 69(6), 439-441.

Reynolds, C. R., \& Kamphaus, R. W. (1992). Behavior Assessment System for Children: Manual. Circle Pines, MN: American Guidance Service, Inc.

Ricker, J. H., Delameter, A. M., \& Hsu, J. (1998). Correlates of regimen adherence in cystic fibrosis. Journal of Clinical Psychology in Medical Settings, 5, 159-172.

Roberts, M. W., Hatzenbuehler, L. C., \& Bean, A. W. (1981). The effects of differential attention and timeout on child noncompliance. Behavior Therapy, 12(93-99).

Robinson, E. A., \& Eyberg, S. M. (1981). The dyadic parent-child interaction coding system: standardization and validation. Journal of Consulting and Clinical Psychology, 49(2), 245-250.

Rortvedt, A. K., \& Miltenberger, R. G. (1994). Analysis of a high-probability instructional sequence and time-out in the treatment of child noncompliance. Journal of Applied Behavior Analysis, 27, 327-330. 
Sanders, M. R., Gravestock, F. M., Wanstall, K., \& Dunne, M. (1991). The relationship between children's treatment-related behaviour problems, age and clinical status in cystic fibrosis. Journal of Paediatrics and Child Health., 27(5), 290-294.

Schuhmann, E. M., Foote, R. C., Eyberg, S. M., Boggs, S. R., \& Algina, J. (1998). Efficacy of Parent-Child Interaction Therapy: Interim report of a randomized trial with short-term maintenance. Journal of Clinical Child Psychology, 27, 34-45.

Singer, L. T., Nofer, J. A., Benso-Szekely, L. J., \& Brooks, L. J. (1991). Behavioral assessment and management of food refusal in children with cystic fibrosis. Journal of Development and Behavioral Pediatrics, 12(2), 115-120.

Socolar, R. R. S., \& Stein, R. E. K. (1996). Maternal discipline of young children: Context, belief, and practice. Developmental and Behavioral Pediatrics, 17, 1-8.

Stark, L. J. (2000). Adherence to diet in chronic conditions: The example of cystic fibrosis. In D. Drotar (Ed.), Promoting Adherence to Medical Treatment in Chronic Childhood Illness. Mahwah, NJ: Lawrence Erlbaum Associates.

Stark, L. J., Bowen, A. M., Tyc, V. L., Evans, S., \& Passero, M. A. (1990). A behavioral approach to increasing calorie consumption in children with cystic fibrosis. Journal of Pediatric Psychology, 15(3), 309-326.

Stark, L. J., Jelalian, E., Mulvihill, M., Powers, S. W., Bowen, A., Spieth, L. E., Keating, K., Evans, S., Creveling, S., Harwood, I., Passero, M. A., \& Hovell, M. (1995). Eating in preschool children with cystic fibrosis and healthy peers: A behavioral analysis. Pediatrics, 95, 210-215. 
Stark, L. J., Jelalian, E., Powers, S. W., Mulvihill, M. M., Opipari, L. C., Bowen, A., Harwood, I., Passero, M. A., Lapey, A., Light, M., \& Hovell, M. F. (2000). Parent and child mealtime behavior in families of children with cystic fibrosis. J Pediatr, 136(2), 195-200.

Stark, L. J., Knapp, L. G., Bowen, A. M., Powers, S. W., Jelalian, E., Evans, S., Passero, M. A., Mulvihill, M. M., \& Hovell, M. (1993). Increasing calorie consumption in children with cystic fibrosis: Replication with 2-year follow-up. Journal of Applied Behavior Analysis, $26(4), 435-450$.

Stark, L. J., Miller, S. T., Plienes, A. J., \& Drabman, R. S. (1987). Behavioral contracting to increase chest physiotherapy. A study of a young cystic fibrosis patient. Behavior Modification, 11(1), 75-86.

Stark, L. J., Opipari, L. C., Spieth, L. E., Jelalian, E., Quittner, A. L., Higgins, L., Mackner, L., Byars, K., Lapey, A., Stallings, V. A., \& Duggan, C. (2003). Contribution of behavior therapy to dietary treatment in cystic fibrosis: A randomized controlled study with a 2 year follow-up. Behavior Therapy, 34(2), 237-258.

Stark, L. J., Powers, S. W., Jelalian, E., Rape, R. N., \& Miller, D. L. (1994). Modifying problematic mealtime interactions of children with cystic fibrosis and their parents via behavioral parent training. Journal of Pediatric Psychology, 19(6), 751-768.

Thompson, R. J., Jr., Gustafson, K. E., Hamlett, K. W., \& Spock, A. (1992a). Psychological adjustment of children with cystic fibrosis: the role of child cognitive processes and maternal adjustment. Journal of Pediatric Psychology, 17(6), 741-755.

Thompson, R. J., Jr., Gustafson, K. E., Hamlett, K. W., \& Spock, A. (1992b). Stress, coping, and family functioning in the psychological adjustment of mothers of children and adolescents with cystic fibrosis. Journal of Pediatric Psychology, 17(5), 573-585. 
Tomezsko, J. L., Stallings, V. A., \& Scanlin, T. F. (1992). Dietary intake of healthy children with cystic fibrosis compared with normal control children. Pediatrics, 90, 547-553.

Vollmer, T. R., \& Iwata, B. A. (1992). Differential reinforcement as treatment for behavior disorders: Procedural and functional variations. Research in Developmental Disabilities, $13,393-417$.

Walker, L. S., Garber, J., \& Van Slyke, D. A. (1995). Do parents excuse the misbehavior of children with physical or emotional symptoms? An investigation of the pediatric sick role. Journal of Pediatric Psychology, 20(3), 329-345. 


\section{Appendix A}

\section{Time out Based Discipline Strategy Treatment Integrity Check}

1) Check the box for each step performed.

2) Calculate the time out integrity score by summing the number of bolded step performed correctly and dividing by the total number of relevant time out items.

The parent gave a direct command.

․ The child complied within 5 seconds

$\checkmark$ The parent gave the child a labeled praise for compliance.

** If the child did not comply within 5 seconds

$\checkmark$ The parent gave the child a time out warning.

$\square$ The child complied with the warning and performs the requested task

口The parent acknowledge the compliance (e.g., "Good job")

$\square$ The child did not comply within 5 seconds of the warning

$\checkmark$ Parent told the child that he/she was going to time out because they did not comply with the command

$\square$ Parent told child to stay in chair until he/she was told to get up

If child did not go to time out independently, the parent escorted him/her

$\square$ Child stays in chair for approximately 3 minutes

$\square$ The parent ignored the child while they are in time out

口 If child leaves chair, parent states a consequence for not sitting in the chair (i.e., removal of privilege)

$\square$ Informs child that the time out is over

$\checkmark$ Re-issues original command

$\checkmark$ Parent repeats above sequence if child does not comply with command (start with a new sheet) 


\section{Appendix B}

Functional Assessment Structured Interview

A) Please describe how you typically approach your child when it is time for (insert treatment component from the CFPC).

1) Behavior: When you initiate this treatment component, how does your child react? Please tell me the sequence of behaviors that your child typically engages in for this treatment component:

a)

b)

c)

d)

- Identify the different behaviors that your child may engage in by breaking them down into the smallest possible units (e.g., "yells NO" or "bites hand" as opposed to" yells \& bites") **Repeat steps 2 through 5 for each behavior the child engages in for this treatment component.

2) Topography: How is this behavior performed?

3) Frequency: How often will your child react to this treatment component in this way?

4) Duration: For how long does your child typically engage in this behavior?

5) Intensity: What is the impact of this behavior? Does it cause any harm? 


\section{Behavior Topography Intensity}

1.

2.

3.

4.

5.

B) Now I want to talk about factors that might influence how your child reacts to the parentinitiated treatment components described above. These are events or conditions that do not necessarily occur immediately before the treatment, but can still influence how your child reacts to the treatment. For example, if your child has had very little sleep the night before, he/she might be cranky and act more difficult than he/she typically does.

\section{1) Medications:}

- Have you noticed that any of the medications that your child is taking can influence his/her mood throughout the day? For example, do any of his/her medications make him/her feel less alert? If so, note the frequency with which these meds are taken and the time of day.

- Do any of your child's medications affect how likely he/she is to complete the treatment? If so, how?

\section{2) Sleep cycle:}

- How many hours of sleep does your child get in a typical night? 
- Does your child take a nap during the day? If so, how long does he/she typically nap for?

- What factors influence whether he/she is able to get more or less sleep?

- Do you notice any changes in his/her behavior when he/she has not had enough sleep?

- Does how much sleep you child gets affect how likely he/she is to complete the treatment? If so, how?

\section{3) Daily schedule:}

- What is your child's typical daily schedule?

1) Morning routine:

2) Mid-day:

3) Afternoon:

4) Evening:

5) Bedtime:

- Have you noticed any changes in your child's behavior when his/her schedule is altered? For example, during holidays when family is visiting?

- Does your child's daily schedule affect how likely he/she is to complete the treatment? If so, how?

\section{4) Family and Community Members:}

- Please tell me the people who your child typically spends time with during the day.

- How does your child typically behave with each of these people? 
- Do you ever notice that your child's behavior is influence by who he/she interacts with?

- Have you noticed that who is in the area can affect how likely your child is to complete the treatment? If so, how?

\section{5) Responsibilities/Chores:}

- Does you child have any responsibilities or chores that he/she is expected to engage in during the average day or week?

- Does your child typically require promoting to perform these tasks? If so, how much prompting and what type?

- Does your child's daily chores affect how likely he/she is to complete the treatment? If so, how?

C) Now I want to find out a little bit about how you typically go about doing your child's treatment regimens. I am going to ask you some fairly detailed questions about the procedures. ** For each treatment component in which the parent reports that the child is not cooperative, repeat these steps.

\section{1) Time of day:}

- What time/times of day do you generally do this treatment?

- Does your child's response to the treatment ever vary depending upon the time of day?

\section{2) Physical setting:}

- Do you always do this treatment component in the same place? 
- Does your child's response to the treatment vary depending upon the setting?

\section{3) Social control:}

- Do you typically do this treatment in the presence of other people?

- Does your child's degree of cooperative behavior/ response to the treatment during the treatment ever vary depending upon who else is present?

\section{4) Activity:}

- Do you notice that your child's behavior during treatment is different depending upon what activities you were planning on doing or what you were doing before the treatment?

- Are there any activities that make it more/less likely that your child will be cooperative with the treatment?

\section{5) Typical child management procedures:}

- What do you typically do when your child is uncooperative?

- What do you typically do when your child is uncooperative during a treatment procedure?

- Do you ever offer your child a reward for completing their treatment?

- Have you ever tried any other strategies to obtain your child's cooperation with medical procedures? 
Appendix $C$

\section{Background Information Form}

\section{Parent Background Information:}

- What is your relation to the child?

- Your gender?

- Your date of birth?

- Your race?

- Your education (highest grade completed/degree)?

- Spouse's education (highest grade completed/degree)?

- Your occupation?

- Spouse's occupation?

- Total family income? $\$$ /per year

Child Background Information:

- What is the gender of this child?

- Child's date of birth?

- Child's race?

- How many other children live in the home?

- What are their ages?

Illness Information:

- At what age was this child first diagnosed with CF?

- Has this child ever been hospitalized?__ If so, why? 
- Has this child experienced any other serious illnesses? If so, please provide the name of the illness and the age of the child when they first experienced this illness.

- Please tell me all of the components of your child's CF regimen and how often they are prescribed:

-

- Please tell me which of the above components you have difficulty obtaining your child's cooperation with and what the specific difficulty is:

\section{$\bullet$}




\section{Appendix D}

\section{Cystic Fibrosis Problem Checklist (CFPC)}

** Below are listed a number of problems that may be encountered by parents in caring for a child with Cystic Fibrosis. Using the key outlined below, please select the alternative that best describes your experience in the past 4 weeks (or since you last completed this measure). If the item is not applicable to your situation, please check the N/A (Not applicable) box. If you would be interested in help to deal with specific problems, check the small box next to your rating.

\begin{tabular}{|c|c|c|c|c|c|c|c|c|}
\hline & & & & Rating & & $\begin{array}{l}\mathrm{He} \\
\mathrm{Wa}\end{array}$ & p & \\
\hline & N/A & $\begin{array}{l}\text { Not } \\
\text { at all }\end{array}$ & $\begin{array}{c}\text { A } \\
\text { little }\end{array}$ & $\begin{array}{l}\text { A fair } \\
\text { amount }\end{array}$ & Much & $\begin{array}{l}\text { Very } \\
\text { much }\end{array}$ & $\mathrm{Y}$ & $\mathrm{N}$ \\
\hline $\begin{array}{l}\text { 1. Your child is reluctant to come for } \\
\text { physiotherapy when called }\end{array}$ & & & & & & & & \\
\hline $\begin{array}{l}\text { 2. Your child will not comply with } \\
\text { your instructions during } \\
\text { physiotherapy }\end{array}$ & & & & & & & & \\
\hline $\begin{array}{l}\text { 3. Your child resists/struggles during } \\
\text { physiotherapy }\end{array}$ & & & & & & & & \\
\hline $\begin{array}{l}\text { 4. Your child complains (cries, } \\
\text { whines, screams) during } \\
\text { physiotherapy }\end{array}$ & & & & & & & & \\
\hline $\begin{array}{l}\text { 5. Your child complains of pain } \\
\text { during physiotherapy }\end{array}$ & & & & & & & & \\
\hline $\begin{array}{l}\text { 6. Your child will not cough when } \\
\text { told to }\end{array}$ & & & & & & & & \\
\hline $\begin{array}{l}\text { 7. Your child will not adopt the } \\
\text { required position during } \\
\text { physiotherapy }\end{array}$ & & & & & & & & \\
\hline $\begin{array}{l}\text { 8. Your child will not take all the } \\
\text { required medication }\end{array}$ & & & & & & & & \\
\hline $\begin{array}{l}\text { 9. Your child takes the required } \\
\text { medication, but requires continued } \\
\text { prompting to do so }\end{array}$ & & & & & & & & \\
\hline $\begin{array}{l}10 . \text { Your child will not eat the } \\
\text { required foods }\end{array}$ & & & & & & & & \\
\hline $\begin{array}{l}\text { 11. Your child will not take enzyme } \\
\text { supplements with meals }\end{array}$ & & & & & & & & \\
\hline $\begin{array}{l}\text { 12. Your child will not take } \\
\text { medication when away from home } \\
\text { (for example, at school) }\end{array}$ & & & & & & & & \\
\hline
\end{tabular}




\begin{tabular}{|c|c|c|c|c|c|c|c|}
\hline & N/A & $\begin{array}{l}\text { Not } \\
\text { at all }\end{array}$ & $\begin{array}{c}\text { A } \\
\text { little }\end{array}$ & $\begin{array}{l}\text { A fair } \\
\text { amount }\end{array}$ & Much & $\begin{array}{l}\text { Very } \\
\text { much }\end{array}$ & $\mathrm{Y}$ \\
\hline $\begin{array}{l}\text { 13. Your child's teacher/daycare } \\
\text { provider is unwilling to ensure that } \\
\text { your child takes his/her medication } \\
\text { when at school }\end{array}$ & & & & & & & \\
\hline $\begin{array}{l}\text { 14. Your child will not drink the } \\
\text { required high energy fluids }\end{array}$ & & & & & & & \\
\hline $\begin{array}{l}\text { 15. Your child will not eat when away } \\
\text { from home }\end{array}$ & & & & & & & \\
\hline $\begin{array}{l}\text { 16. Your child will hold food in } \\
\text { his/her mouth for a long time }\end{array}$ & & & & & & & \\
\hline 17. Your child eats very slowly & & & & & & & \\
\hline $\begin{array}{l}\text { 18. Your child is concerned about } \\
\text { putting on too much weight and } \\
\text { restricts his/her weight }\end{array}$ & & & & & & & \\
\hline $\begin{array}{l}\text { 19. Other family members are critical } \\
\text { of your management of your child }\end{array}$ & & & & & & & \\
\hline $\begin{array}{l}\text { 20. Other people are critical of your } \\
\text { management of your child }\end{array}$ & & & & & & & \\
\hline $\begin{array}{l}\text { 21. Your child remarks that other } \\
\text { children make nasty comments }\end{array}$ & & & & & & & \\
\hline $\begin{array}{l}\text { 22. Your child expresses concern that } \\
\text { he/she feels different from other } \\
\text { children }\end{array}$ & & & & & & & \\
\hline $\begin{array}{l}\text { 23. Your child will not talk about } \\
\text { his/her illness }\end{array}$ & & & & & & & \\
\hline $\begin{array}{l}\text { 24. Your child is generally withdrawn } \\
\text { and sad }\end{array}$ & & & & & & & \\
\hline $\begin{array}{l}\text { 25. Your child expresses the feeling } \\
\text { that he/she is not as good as other } \\
\text { children }\end{array}$ & & & & & & & \\
\hline $\begin{array}{l}\text { 26. You are concerned that your } \\
\text { child's general behaviors deteriorates } \\
\text { when he/she is in the hospital }\end{array}$ & & & & & & & \\
\hline $\begin{array}{l}\text { 27. While hospitalized, you feel that } \\
\text { the hospital staff do not keep you } \\
\text { fully informed about what is going on }\end{array}$ & & & & & & & \\
\hline $\begin{array}{l}\text { 28. When your child comes home } \\
\text { from the hospital, his/her behavior is } \\
\text { more difficult to manage }\end{array}$ & & & & & & & \\
\hline $\begin{array}{l}29 . \text { You need more assistance from } \\
\text { your spouse in the day to day } \\
\text { management of your child's medical } \\
\text { regimen }\end{array}$ & & & & & & & \\
\hline
\end{tabular}




\begin{tabular}{|l|l|l|l|l|l|l|l|l|}
\hline & N/A & $\begin{array}{c}\text { Not } \\
\text { at all }\end{array}$ & $\begin{array}{c}\text { A } \\
\text { little }\end{array}$ & $\begin{array}{c}\text { A fair } \\
\text { amount }\end{array}$ & Much & $\begin{array}{c}\text { Very } \\
\text { much }\end{array}$ & Y & N \\
\hline $\begin{array}{l}\text { 30. Management of your child with } \\
\text { with your spouse }\end{array}$ & & & & & & & & \\
\hline $\begin{array}{l}\text { 31. There is a restriction in the } \\
\text { number of pleasurable activities you } \\
\text { do as a family }\end{array}$ & & & & & & & & \\
\hline $\begin{array}{l}\text { 32. There is difficulty discussing your } \\
\text { child's illness among family members }\end{array}$ & & & & & & & & \\
\hline $\begin{array}{l}\text { 33. Other children in the family are } \\
\text { resentful of the time given to the CF } \\
\text { child }\end{array}$ & & & & & & & & \\
\hline $\begin{array}{l}\text { 34. Your child refuses to insert his/her } \\
\text { nasogastric tube }\end{array}$ & & & & & & & & \\
\hline
\end{tabular}


Appendix E

\section{Observational Assessment Behavior Codes Definitions}

\section{PARENT BEHAVIORS: VERBAL}

Direct Commands: A clearly stated order, or demand in declarative form. The statement must be sufficiently specific as to indicate the behavior that is expected from the child (e.g., "Please take your shirt off for your CPT"; "Please swallow this pill"; "Please come to the dinner table").

Indirect Commands: An order, demand, or direction for a response that is implied, nonspecific, or stated in question form (e.g., "Why don't you eat the rest of your food, Okay?"; "Let's get ready for CPT"; "Here you go").

Labeled Praise: Any specific verbalization that expresses a favorable judgment on the treatment-related behavior of the child (e.g., "Thank you for taking your shirt off so quickly!"; "Nice work taking that pill right away, what a big helper you are"; "WOW, you are a really good eater")

Unlabeled Praise: A nonspecific verbalization that expresses a favorable judgment on the treatment-related behavior (e.g., "Great”; "Good job”; "Perfect!").

Negative Verbal Attention: Verbal comments or questions that are directed to the child and express negative judgment or vague threats (e.g., "No"; "Stop it"; "I have had about enough of that"; "Just wait until your father comes home")

General Verbal Attention: Verbal comments or questions that are directed to the child but would not fit into any of the above categories (e.g., "How was school?"; "We will be eating potatoes later"; “What's that?”). 


\section{PARENT BEHAVIORS: PHYSICAL}

Prompt: The parent physically guides or prompts the child to complete a demand or task (e.g., takes off shirt for child when they had previously asked the child to do so, holds child's hand to bring fork up the child's mouth, carries child to time out).

Physical Negative: The parent makes contact with the child's body in an aversive manner (e.g., spank, squeeze, or to tap).

Physical Positive: The parent makes contact with the child's body in a positive way (e.g., stroking the child's hair, kissing the child's head, hugging the child).

Tangible delivery: The parent delivers a tangible item to the child (e.g., stuffed animal, candy, toy).

\section{CHILD BEHAVIORS:}

Compliance: Child obeys, begins to obey, or attempts to obey a direct or indirect parental command (e.g., starts to take shirt off for CPT; opens mouth for pill; picks up fork to eat more food) within 5 seconds.

\section{PROCEDURE CODES:}

Time out onset: Indicated that the parent has started a time out. This can either be formally "You choose not to listen, you are going into time out" or informally where the parent might place the child in the time out chair or say "You are in time out now."

Time out end: Indicated that the parent has stopped a time out, this is typically when the child complies with the original command. 


\section{Appendix $F$}

$\underline{\text { Conditional Probabilities Tables }}$

\begin{tabular}{|c|c|}
\hline $\begin{array}{c}\text { Intervals of Parent } \\
\text { Behaviors }\end{array}$ & Parent Behavior Based Conditional Probabilities \\
\hline & $\frac{\text { \# of intervals parent beh. followed w/in } 5 \text { s by child comp }}{\text { total \# of intervals the } \mathrm{p} . \text { beh occurred }}$ \\
\hline Direct Command (DC) & $\frac{\text { \# of DC intervals followed } \mathrm{w} / \text { in } 5 \mathrm{~s} \text { by child compliance }}{\text { total \# of intervals DC occurred }}$ \\
\hline Indirect Command (IC) & $\frac{\text { \# of IC intervals followed w/in } 5 \mathrm{~s} \text { by child compliance }}{\text { total \# of intervals IC occurred }}$ \\
\hline $\begin{array}{l}\text { Negative Verbal } \\
\text { Attention (NVA) }\end{array}$ & $\frac{\text { \# of NVA intervals followed w/in 5s by child compliance }}{\text { total \# of intervals NVA occurred }}$ \\
\hline $\begin{array}{l}\text { General Verbal } \\
\text { Attention (GVA) }\end{array}$ & $\frac{\text { \# of GVA intervals followed w/in 5s by child compliance }}{\text { total \# of intervals GVA occurred }}$ \\
\hline $\begin{array}{l}\text { Physical } \\
\text { Prompt/Guidance } \\
\text { (PPG) }\end{array}$ & $\frac{\text { \# of PPG intervals followed } \mathrm{w} / \text { in } 5 \mathrm{~s} \text { by child compliance }}{\text { total \# of intervals PPG occurred }}$ \\
\hline Physical Negative (PN) & $\frac{\# \text { of PN intervals followed w/in } 5 \mathrm{~s} \text { by child compliance }}{\text { total \# of intervals PN occurred }}$ \\
\hline Physical Positive (PP) & $\frac{\# \text { of PP intervals followed } \mathrm{w} / \text { in } 5 \mathrm{~s} \text { by child compliance }}{\text { total \# of intervals PP occurred }}$ \\
\hline Tangible Delivery (TD) & $\frac{\# \text { of TD intervals followed w/in 5s by child compliance }}{\text { total \# of intervals TD occurred }}$ \\
\hline \multicolumn{2}{|l|}{ Procedure Codes } \\
\hline Time-out onset (TO) & $\frac{\# \text { of TO intervals followed w/in } 5 \mathrm{~s} \text { by child compliance }}{\text { total \# of intervals TO occurred }}$ \\
\hline Time-out end (TOE) & $\begin{array}{c}\text { \# of TOE intervals followed w/in } 5 \text { s by child compliance } \\
\text { total \# of intervals TOE occurred }\end{array}$ \\
\hline
\end{tabular}




\begin{tabular}{|c|c|}
\hline $\begin{array}{c}\text { Intervals of Parent } \\
\text { Behaviors }\end{array}$ & Child Behavior Based Conditional Probabilities \\
\hline & $\frac{\# \text { of intervals parent beh. followed } \mathrm{w} / \text { in } 5 \mathrm{~s} \text { by child comp. }}{\text { total \# of intervals the child was compliant }}$ \\
\hline Direct Command (DC) & $\frac{\text { \# of DC intervals followed w/in } 5 \mathrm{~s} \text { by child compliance }}{\text { total \# of intervals the child was compliant }}$ \\
\hline Indirect Command (IC) & $\frac{\# \text { of IC intervals followed w/in } 5 \mathrm{~s} \text { by child compliance }}{\text { total \# of intervals the child was compliant }}$ \\
\hline $\begin{array}{l}\text { Negative Verbal } \\
\text { Attention (NVA) }\end{array}$ & $\frac{\text { \# of NVA intervals followed w/in } 5 \mathrm{~s} \text { by child compliance }}{\text { total \# of intervals the child was compliant }}$ \\
\hline $\begin{array}{l}\text { General Verbal } \\
\text { Attention (GVA) }\end{array}$ & $\frac{\text { \# of GVA intervals followed w/in } 5 \mathrm{~s} \text { by child compliance }}{\text { total \# of intervals the child was compliant }}$ \\
\hline $\begin{array}{l}\text { Physical } \\
\text { Prompt/Guidance } \\
\text { (PPG) }\end{array}$ & $\frac{\# \text { of PPG intervals followed } \mathrm{w} / \text { in } 5 \mathrm{~s} \text { by child compliance }}{\text { total } \# \text { of intervals the child was compliant }}$ \\
\hline Physical Negative (PN) & $\frac{\# \text { of PN intervals followed } \mathrm{w} / \text { in } 5 \mathrm{~s} \text { by child compliance }}{\text { total } \# \text { of intervals the child was compliant }}$ \\
\hline Physical Positive (PP) & $\begin{array}{c}\text { \# of PP intervals followed w/in } 5 \mathrm{~s} \text { by child compliance } \\
\text { total \# of intervals the child was compliant }\end{array}$ \\
\hline Tangible Delivery (TD) & $\frac{\# \text { of TD intervals followed } \mathrm{w} / \text { in } 5 \mathrm{~s} \text { by child compliance }}{\text { total \# of intervals the child was compliant }}$ \\
\hline \multicolumn{2}{|l|}{ Procedure Codes } \\
\hline Time-out onset (TO) & $\frac{\# \text { of TO intervals followed } \mathrm{w} / \text { in } 5 \mathrm{~s} \text { by child compliance }}{\text { total \# of intervals the child was compliant }}$ \\
\hline Time-out end (TOE) & $\frac{\# \text { of TOE intervals followed w/in } 5 \text { s by child compliance }}{\text { total \# of intervals the child was compliant }}$ \\
\hline
\end{tabular}




\section{Appendix $G$}

\section{Time Out Based Discipline Strategy Quiz}

- Please circle the letter that best completes for each statement.

1) When I want my child to participate in a CF treatment, I should:

a) tell them all of the steps that I want them to complete for that particular procedure (i.e., "Drink 3 sips of milk, take one blue pill, then take one red pill, and then eat 5 bites of potatoes.")

b) tell them what I want them to do using pointing only (i.e., point to milk and then point to my child).

c) give them a simple, clear, and positively framed instruction (i.e., "Please swallow your red pill.")

2) After I give my child a command, I should:

a) wait for 5 seconds to see if they have started to cooperate

b) immediately issue a prompt if they have not started to cooperate after I issued the command (i.e., "Now, come on, today...")

c) turn my back for 10 seconds and see what they will do after that

3) If my child cooperates with my request I should:

a) ignore their cooperation, because otherwise I might make them think that it is unusual that they cooperate

b) praise their behavior so that they know what they did right

c) give them a treat, like a cookie, so that they will keep up the good behaviors

4) If my child doesn't cooperate with my command I should:

a) put them in time-out right away

b) wait 20 seconds without doing anything

c) give them a warning that if they do not cooperate they will go to time-out

5) When I take my child to time-out I should:

a) tell them that they must go to time-out because they did not listen to my command (i.e., "You choose not to listen when I asked you to take your pill, so now you must go to time-out)

b) not make them go if they promise (on the way to the time-out chair) to be good and listen

c) say nothing about why they are going and just make them go

6) If my child refuses to go to time-out I should:

a) not make them go

b) explain to them again why they have to go and see if that will make them go

c) escort them into time-out by holding their hand, or, when necessary carrying them in a barrel hold 
7) When my child is in time-out I should:

a) talk to them in a quiet voice while I explain what they did wrong and to seeing if they have any questions about why they are in time-out

b) ignore them as much as possible

c) turn on the TV or radio in the same room to distract myself

8) If my child leaves the time-out chair during time-out I should:

a) ask them if they are ready to complete their treatment

b) ask them to explain why they had a time-out

c) inform them that they will lose a privilege (i.e., TV time) if they do not return to the time-out chair

9) When the 3 minutes of time-out have been completed I should:

a) re-issue the original command that got them into time-out

b) give my child a big hug and tell them I love them and apologize for having put them in time-out

c) give my child a chance to put me in time-out

10) If my child will still not complete the original command after a time-out I should:

a) forget about that particular command and give them a new one

b) given them the choice of time-out again, and put them into time-out if they still will not be cooperative

c) take a 10 minute break and then ask them again. 


\section{Appendix $H$}

\section{Exit Interview}

1) What do you like about your typical child management strategy (i.e., the one that you used during the first part of this study)?

2) What did you not like about your typical child management strategy?

3) What do you like about the time out procedure?

4) What do you not like about the time out procedure?

5) Do you intend to continue using the time out procedure for treatment-related behavior problems?

6) Did you use the time out procedure for child behavior difficulties unrelated to treatment difficulties?

At the end of this interview, show the parent the graphed data of child compliance during all conditions of the study. 
Appendix I

\section{Child Exit Interview}

1) What do you like about (insert parent's typical child management strategy)?

2) What did you not like about (insert typical child management strategy)?

3) What do you like about the time-out?

4) What do you not like about the time-out?

5) Would you prefer if your (parent) kept on using time-out or would you prefer if they went back to (insert typical child management strategy) for times when you don't listen about medications?

6) Did your (parent) use time-out for times when you didn't listen at times other than medication times? 


\section{Appendix $J$}

\section{Video Camera Instructions}

1) First, unfold the tripod, making sure that all of the legs are fully extended and locked in place.

2) Set up the camera on the tripod. Make sure that it is securely positioned on the tripod by snapping it in place.

3) Place the camera in a corner of the room, aimed at the area of the room where the treatment will be performed. Adjust the camera so that you will be able to film as much of the treatment as possible.

4) Plug the camera in by inserting the outlet connector into the "DC IN" plug in the back of the camera (below the eyepiece).

5) Turn the camera on by removing the lens cap and moving the power switch up (located on the back right of the camera), so that the left side points down to "camera."

6) Make sure that the time and date are displayed. This should happen automatically, UNLESS you are using the screen (instead of the eyepiece) and flip it to face the family. As long as you keep the screen closed, the date will be displayed.

7) Place a tape in the camera (if this hasn't already been done). To do this, first pop up the camera control panel (the portion of the camera with "STOP," "REW," etc. on it), then push the blue "EJECT" button under this panel. When you push the tape in it will automatically close and you only need to flip the panel back down.

8) Ensure that the tape has adequate space on it. If not sure, put in a new tape. If you are starting a new tape, make sure you place a labeling sticker (found in the new tape case) on the tape.

9) Now you are ready to roll! Simply push the red button near the power switch to begin recording. Push the same button to stop recording. 


\section{Appendix $K$}

\section{Time out Based Discipline Strategy Didactic Script Based on "Parenting the Strong-Willed Child: A Clinically Proven Five-Week Program for Parents of Two- to Six-Year-Olds" (Forehand \& Long, 2002)}

\section{GIVING DIRECTIONS}

When you ask your child to do something, your directions need to be clear. If you are not clear, you can't expect your child to do what you want. There are good and bad ways of giving directions. It is often hard for parents to give good directions.

Tips for giving GOOD directions:

(1) Before giving a direction, make sure you have your child's attention and eye contact.

(2) Use a firm, not loud, voice.

(3) Use a direction that is specific and simple.

(4) If possible, use physical gestures like pointing.

(5) Use positive directions ("do this") instead of negative directions ("don't do this"). For example say, "Please lay down," instead of "Stop getting up." Children understand "do's" better than "don'ts." In addition, you have an opportunity to reinforce (attend and/or reward) a behavior when your child does what you ask.

(6) If your child follows your directions, make sure that you pay attention and reward! The best way to do this is to praise your child for the specific behavior that they did. So, if your child listened to your request, you should praise them form listening "Thank you for listening."

(7) Never give a direction that you are not prepared to enforce. If you child does not do as he/she is told and you do nothing, your child has learned that you do not mean what you say.

There are four main types of POOR directions that you should avoid:

(1) Chain Directions: This is when a parent gives a child several directions at one time. For example, "Eat 4 bites of mashed potatoes, take your pill, and drink the rest of your milk." The problem with chain directions is that a child's brain is different than an adult. It can't process as much information at one time as an adult's brain can. Therefore, children can forget some of the directions. It's much better to break the directions down into smaller steps, one at a time, and praise compliance.

(2) Vague directions: These are directions that are not very clear or specific. For example, "Be good." The problem is that neither you nor your child may know what you mean. What you mean and what he/she thinks you mean might be very different. It's much better to be very clear. For example, "Take one pill" or "Cough." The more specific you are, the more likely he'll do as he's told. 
(3) Question directions: These are directions given in the form of questions. For example, "Would you like to do your CPT now?" The problem is that your child can say, "No." You should avoid setting yourself up like this. Simply avoid giving directions in the form of questions.

(4) Directions followed by a reason: This is when a parent gives a direction, then an explanation. For example, "Please take your pills because otherwise your might get sick and have to go to the doctor again and it so a really long drive away." The problem is that the child often forgets the original direction. Remember, a child's brain can't hold very much at one time. It's much better to give the reason first if you choose to give one. For example, "Because your need to stay healthy, please take your pill." The direction should be the last thing you say.

\section{REMEMBER:}

(1) Use simple and clear directions.

(2) Praise your child when he/she follows a direction by telling them what they did that you like.

(3) Never give a direction you're not prepared to enforce.

Tips for deciding whether your child listened:

1) If you child has not started to do what you asked for them to do within 5 seconds, your child is dawdling. While you are waiting to see if they are going to listen to you, don't say anything, just wait and count to 5 in your head. If they haven't starting doing what you asked them to do at the end of 5 seconds, then they are being noncooperative with your treatment request and it is time for a warning for time out.

\section{TIME OUT}

Everyone has his/her own method of Time out. However, there are good and bad methods of using time outs. What is important is that you and your child fully understand and agree on: (1) what time outs are for, (2) where time outs will occur, (3) what the exact rules and steps are for time out, and (4) that time out occur every time that they should. You and your child should discuss in detail and practice these guidelines when you are both in good spirits before using time outs.

Time out means "time out from anything reinforcing (attention and rewards)." So, your child should spend several minutes in a very boring place immediately following the bad behavior. It's used for behaviors that just can't be ignored.

Time outs are superior to hitting and yelling for several reasons. For example, hitting and yelling will teach a child that aggression solves problems and that the bigger person rules. Spanking only works when the child is small. Also, when children are emotionally aroused, such as when being spanked, there is a low likelihood that they will remember what they did to deserve the spanking.

If, after one warning, your child doesn't follow a direction you give, you should use time out. For example, let's say you tell your child to take a pill. If he/she starts doing this in 5 seconds, pay attention and praise. If he/she doesn't start in 5 seconds, say, "If you don't take your pill, you'll have to take a time out." If he/she doesn't start taking the pill within 5 seconds, he/she should have to take a time out.

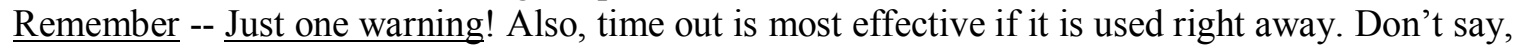
"You'll have to take a time out later." 
The first thing you need to do is choose a time out place in your home. These are things you need to consider.

(1) Choose a place away from toys, people, windows, TVs, radios, and anything else he/she likes. There should be no breakable things nearby.

(2) The child's bedroom is typically not a good place for time out. The bedroom often has too many things in it he/she likes. If you need to use the bedroom as a time out area, you should remove toys from the room.

(3) If you use a separate room, do not turn off the lights. This will only scare your child. Also, never use a closet.

(4) Often the best place is at the end of a hallway. Most of the time this is a place away from people and things he/she likes.

(5) It is often helpful to put a small chair in the time out place. This will serve as a reminder to your child. It will also make it easier to keep him/her in the time out place. The chair should not be put where he/she can kick the wall.

Now, you need to know the best way to use time out. As an example, let's say that you've decided to use time out for a particular behavior. Then what should you do?

$\underline{\text { Steps for effective time out: }}$

(1) Tell your child, "Because you did... you have to take a time out." You should say this only once. Say it in a calm but firm voice.

Do NOT lecture, scold, or argue.

Do NOT accept any excuses.

Do NOT talk to him/her while taking him/her to the chair. Ignore shouting, protesting, and promises to be good.

(2) If he/she refuses to go, physically guide or carry him/her to the chair.

(3) When you get to the chair, tell him/her to sit down.

(4) Tell him/her to stay in the chair until you say he/she can get up.

(5) Use a back up room or a two chair hold if he/she refuses to stay in the chair.

Do NOT let anyone talk with him/her while he/she is in the chair.

Do NOT let him/her play with anything while he's in the chair.

(5) After 3 minutes, tell him/her he/she can get up. If he/she had to go to time out for not following a direction, give the direction again. You must do this or he'll learn he/she can get out of doing things by taking a time out.

(6) If he/she follows the directions given after his/her time out, say in a natural voice, "I like it when you do as you're told." You should not praise him/her anymore than this. However, also praise the next positive thing he/she does. 
(8) If he/she doesn't follow the direction you give after time out, repeat the time out procedure. It might take several times before he/she learns that you mean what you say.

(9) After _ (decided upon number of time outs with the parents) time outs, you may find it necessary to use physical guidance so that you can continue with your day. Physical guidance consists of gently, but firmly, guiding your child through the requested behavior. If this is not possible (for example, they refuse to swallow) removal of a daily privilege should be used.

Let's go back to the end of time out for a moment. Your child needs to be quiet for at least the last 30 seconds of time out. Do not let him/her get up from the chair if he/she is still screaming or kicking at the end of the 3 minutes. Wait until he/she has been quiet for at least 30 seconds beyond the 3 minutes, then let him/her get up.

When parents first start using time out, many children scream or cry. This is normal and you should just ignore it. He'll likely stop this after several time outs.

When you first start using time out, your child might get up before 3 minutes is over. If he/she does this, tell him/her his/her time is starting over. If he/she continues to leave the chair, you have several options. You can place him/her in a safe, well-lit room (e.g., laundry room, bedroom) or you can return him/her to the chair and tell him/her he/she is losing a privilege. For example, say in a calm voice, "If you get up again, you can't ride your bike the rest of the day." Remember, if you say it, do it!

If you follow all these directions, time out should work for you. But remember, it's not an easy method to learn. Don't use it until you learn to do it the right way.

\section{REMEMBER:}

(1) Use time out immediately after the treatment refusal behavior.

(2) Never threaten time out if you're not willing to follow through and use it.

(3) Only use time out for the targeted treatment refusal behavior! After the study is over you can certainly use it for other behaviors too, but for now, we need to be sure that it is working on the treatment behaviors only.

\section{FLOW CHART AFTER A GOOD DIRECTION IS ISSUED}

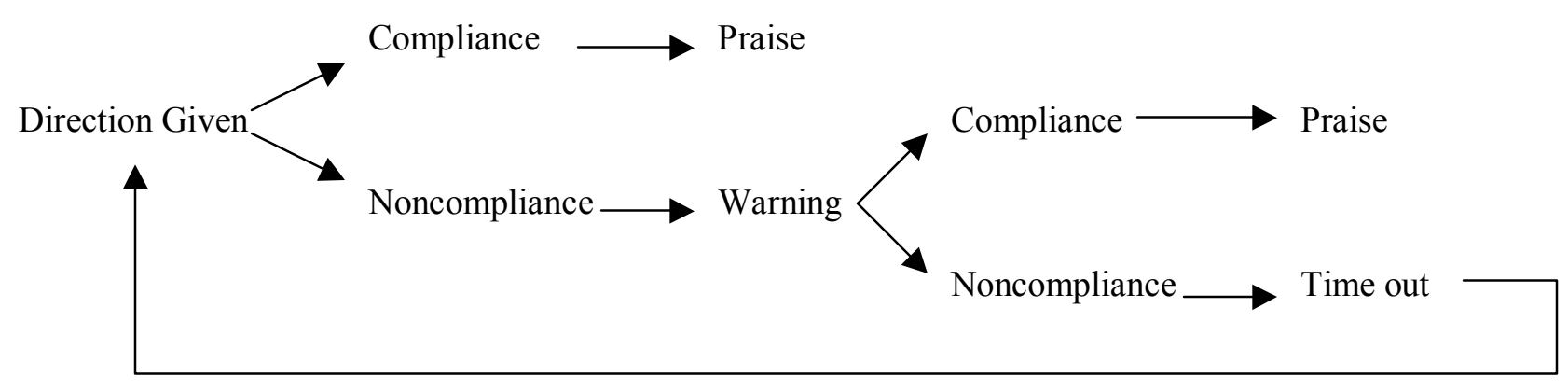




\section{FINAL THOUGHTS}

(1) You will need to work on using the principles you have learned. It should feel uncomfortable and unnatural at first, that is good, it means that your behavior is changing and your child's behavior will change in response.

(2) Plan to re-read this handout every couple of days to tune-up and refocus. If you are straying from the suggestions and you and your child are falling back into your old patterns, become re-oriented and get back to work.

(3) Above all, try to be consistent.

(4) We realize that being a parent is both the most difficult and painful job and also the most rewarding job on the planet. Give yourself some credit and take care of yourself. 
Appendix $L$

\section{TIME OUT BASED DISCIPLINE STRATEGY FLOW CHART}

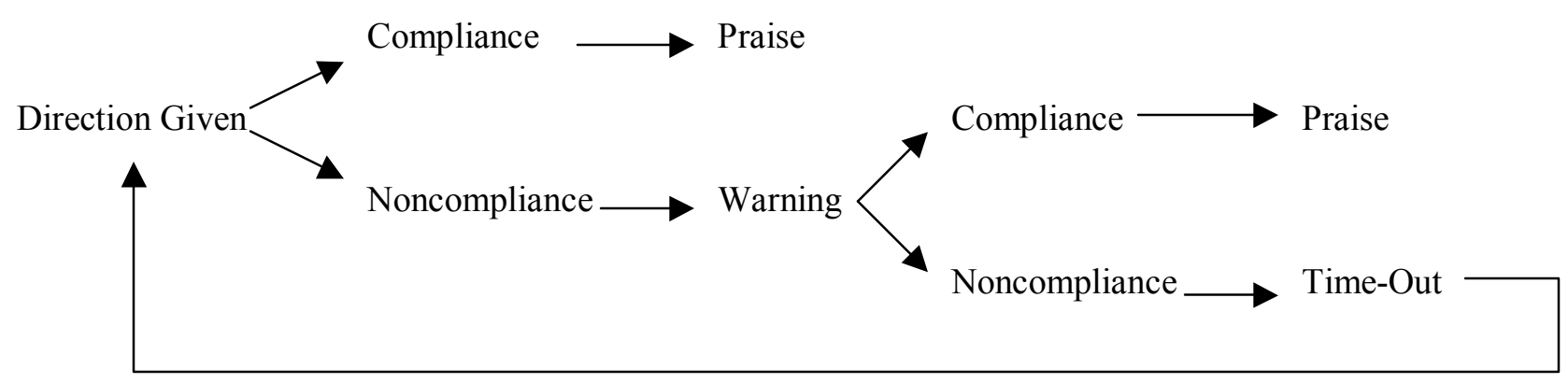


Table 1

Mean Agreement Percentages for Observational Assessment

\begin{tabular}{|c|c|c|c|}
\hline Behavior & $\begin{array}{l}\text { Occurrence } \\
\text { Agreement }\end{array}$ & $\begin{array}{l}\text { Non-occurrence } \\
\text { agreement }\end{array}$ & Total Agreement \\
\hline \multicolumn{4}{|l|}{ Child Behaviors } \\
\hline Compliance & $81 \%$ & $98 \%$ & $97 \%$ \\
\hline Problem behaviors & $82 \%$ & $98 \%$ & $96 \%$ \\
\hline \multicolumn{4}{|l|}{ Leaving time out } \\
\hline Crying & $100 \%$ & $100 \%$ & $100 \%$ \\
\hline \multicolumn{4}{|l|}{ Parent Behaviors } \\
\hline Direct Commands & $88 \%$ & $95 \%$ & $93 \%$ \\
\hline Indirect Commands & $81 \%$ & $86 \%$ & $82 \%$ \\
\hline Labeled Praise & $79 \%$ & $85 \%$ & $81 \%$ \\
\hline Unlabeled Praise & $79 \%$ & $84 \%$ & $80 \%$ \\
\hline Negative Verbal Attention & $*$ & $*$ & $*$ \\
\hline General Verbal Attention & $85 \%$ & $93 \%$ & $90 \%$ \\
\hline Physical Positive & $88 \%$ & $95 \%$ & $93 \%$ \\
\hline Physical Negative & $*$ & $*$ & $*$ \\
\hline Physical Prompt/Guidance & $82 \%$ & $87 \%$ & $84 \%$ \\
\hline \multicolumn{4}{|l|}{ Procedure Codes } \\
\hline Time out onset & $*$ & $*$ & $*$ \\
\hline Time out end & $*$ & $*$ & $*$ \\
\hline
\end{tabular}

Note. Cell where behavior did not occur were left blank. 
Table 2

Conditional Probability Percentages of Child Compliance within 5-seconds of Commands and Prompts

\begin{tabular}{|c|c|c|c|c|c|c|}
\hline \multirow[t]{2}{*}{ Parent Behavior } & \multirow[t]{2}{*}{ Child } & Method of & \multirow[t]{2}{*}{ Baseline } & \multirow[t]{2}{*}{ Intervention } & \multirow[t]{2}{*}{ Reversal } & \multirow[t]{2}{*}{ Intervention } \\
\hline & & Calculation & & & & \\
\hline \multirow[t]{4}{*}{ Direct Commands } & Mary & Parent & $48 \%$ & $71 \%$ & $54 \%$ & $69 \%$ \\
\hline & & Child & $76 \%$ & $74 \%$ & $59 \%$ & $58 \%$ \\
\hline & Janis & Parent & $0 \%$ & $98 \%$ & $87 \%$ & $100 \%$ \\
\hline & & Child & $0 \%$ & $94 \%$ & $88 \%$ & $82 \%$ \\
\hline \multirow[t]{4}{*}{ Indirect Commands } & Mary & Parent & $37 \%$ & $37 \%$ & $46 \%$ & $65 \%$ \\
\hline & & Child & $32 \%$ & $21 \%$ & $38 \%$ & $41 \%$ \\
\hline & Janis & Parent & $0 \%$ & $19 \%$ & $40 \%$ & $50 \%$ \\
\hline & & Child & $0 \%$ & $6 \%$ & $12 \%$ & $24 \%$ \\
\hline \multirow[t]{4}{*}{ Prompts } & Mary & Parent & $7 \%$ & $28 \%$ & $14 \%$ & $26 \%$ \\
\hline & & Child & $2 \%$ & $5 \%$ & $4 \%$ & $6 \%$ \\
\hline & Janis & Parent & $0 \%$ & & & \\
\hline & & Child & $0 \%$ & & & \\
\hline
\end{tabular}

Note. Cells where parent behavior did not occur were left blank. 
Table 3

Frequencies of Desirable, Undesirable, and Neutral Parent Behaviors by Condition

\begin{tabular}{|c|c|c|c|c|c|c|}
\hline & Parent Behaviors & Child & Baseline & Intervention & Reversal & Intervention \\
\hline \multirow[t]{10}{*}{ Desirable } & \multirow[t]{2}{*}{ Direct Commands } & Mary & $35 \%$ & $35 \%$ & $29 \%$ & $26 \%$ \\
\hline & & Janis & $17 \%$ & $64 \%$ & $47 \%$ & $35 \%$ \\
\hline & \multirow[t]{2}{*}{ Labeled Praise } & Mary & $1.7 \%$ & $2 \%$ & $1 \%$ & $6 \%$ \\
\hline & & Janis & $0 \%$ & $7 \%$ & $2 \%$ & $6 \%$ \\
\hline & \multirow[t]{2}{*}{ Unlabeled Praise } & Mary & $0.3 \%$ & $15 \%$ & $3 \%$ & $6 \%$ \\
\hline & & Janis & $0 \%$ & $16 \%$ & $20 \%$ & $17 \%$ \\
\hline & \multirow[t]{2}{*}{ Physical Positive } & Mary & $2 \%$ & $2 \%$ & $2 \%$ & $0 \%$ \\
\hline & & Janis & $0 \%$ & $0 \%$ & $0 \%$ & $0 \%$ \\
\hline & \multirow[t]{2}{*}{ Sum of Desirable } & Mary & $39 \%$ & $54 \%$ & $35 \%$ & $38 \%$ \\
\hline & & Janis & $17 \%$ & $87 \%$ & $69 \%$ & $58 \%$ \\
\hline \multirow[t]{8}{*}{ Undesirable } & \multirow[t]{2}{*}{ Indirect Commands } & Mary & $17 \%$ & $13 \%$ & $20 \%$ & $19 \%$ \\
\hline & & Janis & $8 \%$ & $4 \%$ & $6 \%$ & $15 \%$ \\
\hline & \multirow[t]{2}{*}{ Negative Verbal Attention } & Mary & $1 \%$ & $1 \%$ & $1.5 \%$ & $2.5 \%$ \\
\hline & & Janis & $8 \%$ & $0 \%$ & $0 \%$ & $0 \%$ \\
\hline & \multirow[t]{2}{*}{ Physical Negative } & Mary & $0 \%$ & $0 \%$ & $0.5 \%$ & $0 \%$ \\
\hline & & Janis & $0 \%$ & $0 \%$ & $0 \%$ & $0 \%$ \\
\hline & \multirow[t]{2}{*}{ Sum of Undesirable } & Mary & $18 \%$ & $14 \%$ & $22 \%$ & $21.5 \%$ \\
\hline & & Janis & $16 \%$ & $4 \%$ & $6 \%$ & $15 \%$ \\
\hline \multirow[t]{10}{*}{ Neutral } & \multirow[t]{2}{*}{ General Verbal Attention } & Mary & $38 \%$ & $30 \%$ & $41 \%$ & $37 \%$ \\
\hline & & Janis & $59 \%$ & $9 \%$ & $25 \%$ & $27 \%$ \\
\hline & \multirow[t]{2}{*}{ Physical Prompt/Guidance } & Mary & $5 \%$ & $1 \%$ & $2 \%$ & $2 \%$ \\
\hline & & Janis & $8 \%$ & $0 \%$ & $0 \%$ & $0 \%$ \\
\hline & \multirow[t]{2}{*}{ Time Out Onset \& End } & Mary & $0 \%$ & $1 \%$ & $0 \%$ & $1.5 \%$ \\
\hline & & Janis & $0 \%$ & $0 \%$ & $0 \%$ & $0 \%$ \\
\hline & \multirow[t]{2}{*}{ Tangible Delivery } & Mary & $0 \%$ & $0 \%$ & $0 \%$ & $0 \%$ \\
\hline & & Janis & $0 \%$ & $0 \%$ & $0 \%$ & $0 \%$ \\
\hline & \multirow[t]{2}{*}{ Sum of Neutral } & Mary & $43 \%$ & $32 \%$ & $43 \%$ & $38.5 \%$ \\
\hline & & Janis & $67 \%$ & $9 \%$ & $25 \%$ & $27 \%$ \\
\hline
\end{tabular}


Table 4

Baseline and Study Completion BASC-PRS scores for Mary and Janis

\begin{tabular}{|c|c|c|c|c|}
\hline \multirow[t]{2}{*}{ Clinical Scales } & Mary & Mary & Janis & Janis \\
\hline & Baseline & Completion & Reversal & Completion \\
\hline Hyperactivity & 64* & 42 & 34 & 30 \\
\hline Aggression & 54 & 37 & 37 & 37 \\
\hline Anxiety & 57 & $62^{*}$ & 50 & 57 \\
\hline Depression & $64^{*}$ & 49 & 34 & 34 \\
\hline Somatization & $66^{*}$ & 57 & 49 & 51 \\
\hline Atypicality & 41 & 44 & 44 & 37 \\
\hline Withdrawal & 51 & 35 & $61^{*}$ & 53 \\
\hline Attention Problems & $65^{*}$ & 47 & 28 & 28 \\
\hline \multicolumn{5}{|l|}{ Adaptive Scales } \\
\hline Adaptability & 49 & 68 & $39^{*}$ & $36^{*}$ \\
\hline Social Skills & 62 & 70 & 52 & 52 \\
\hline \multicolumn{5}{|l|}{ Composite Scales } \\
\hline Externalizing Problems & $60^{*}$ & 38 & 34 & 32 \\
\hline Internalizing Problems & $66^{*}$ & 58 & 43 & 47 \\
\hline Behavioral Symptoms Index & $61^{*}$ & 45 & 33 & 32 \\
\hline Adaptive Skills & 56 & 71 & 45 & 43 \\
\hline
\end{tabular}

Note. T-Score between 60 and 69 on any clinical scale and between 31 and 40 on any adaptive scale is considered "at-risk" and indicated by *. 


\section{Figure Caption}

Figure 1. Child compliance with parent prompts, direct and indirect commands for Mary (top panel) and Janis (bottom panel) across study conditions.

Figure 2. Percentage of direct commands, labeled praise, and compliance praised by condition for Mary and Janis.

Figure 3. CFPC problem intensity scores for Mary and Janis by condition.

Figure 4. CFPC problem item scores for Mary and Janis. 


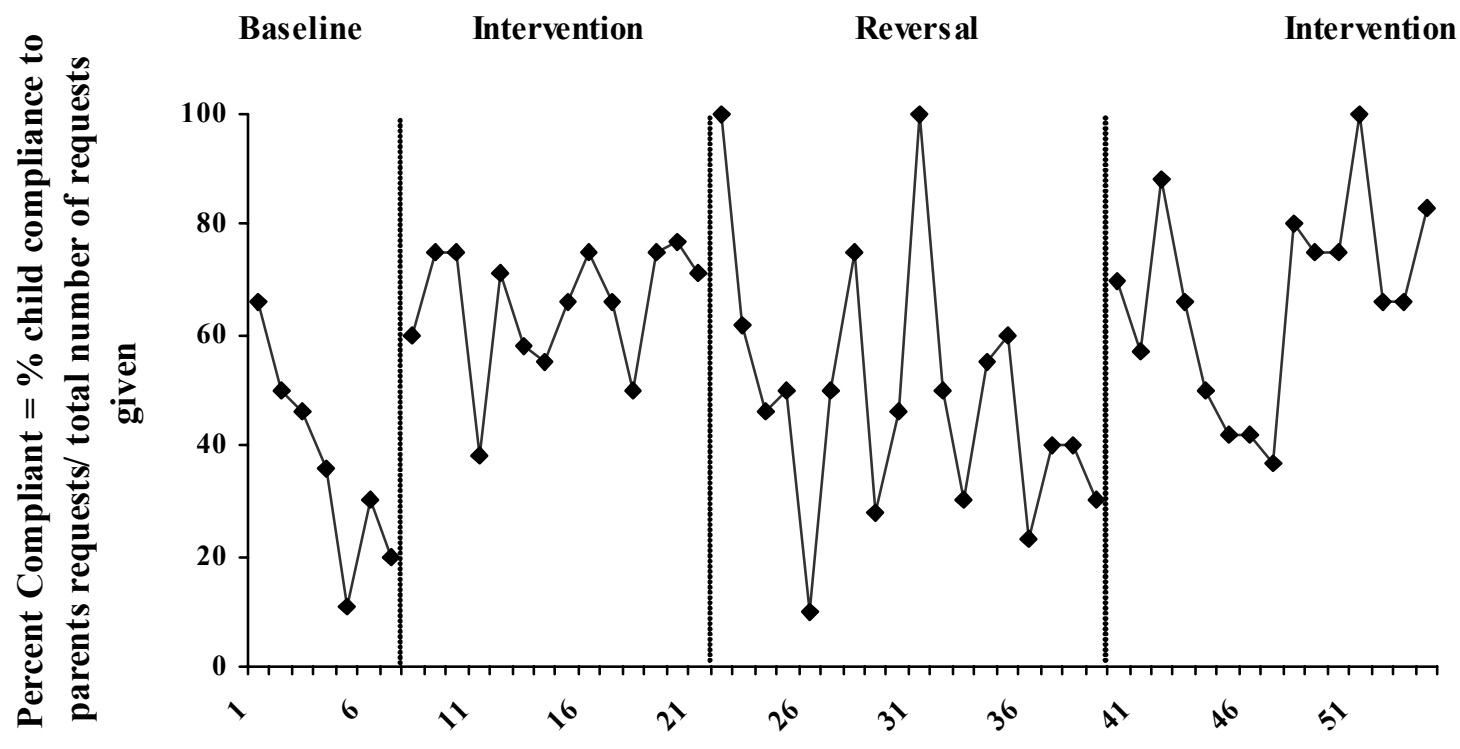

Mary Smith Observations

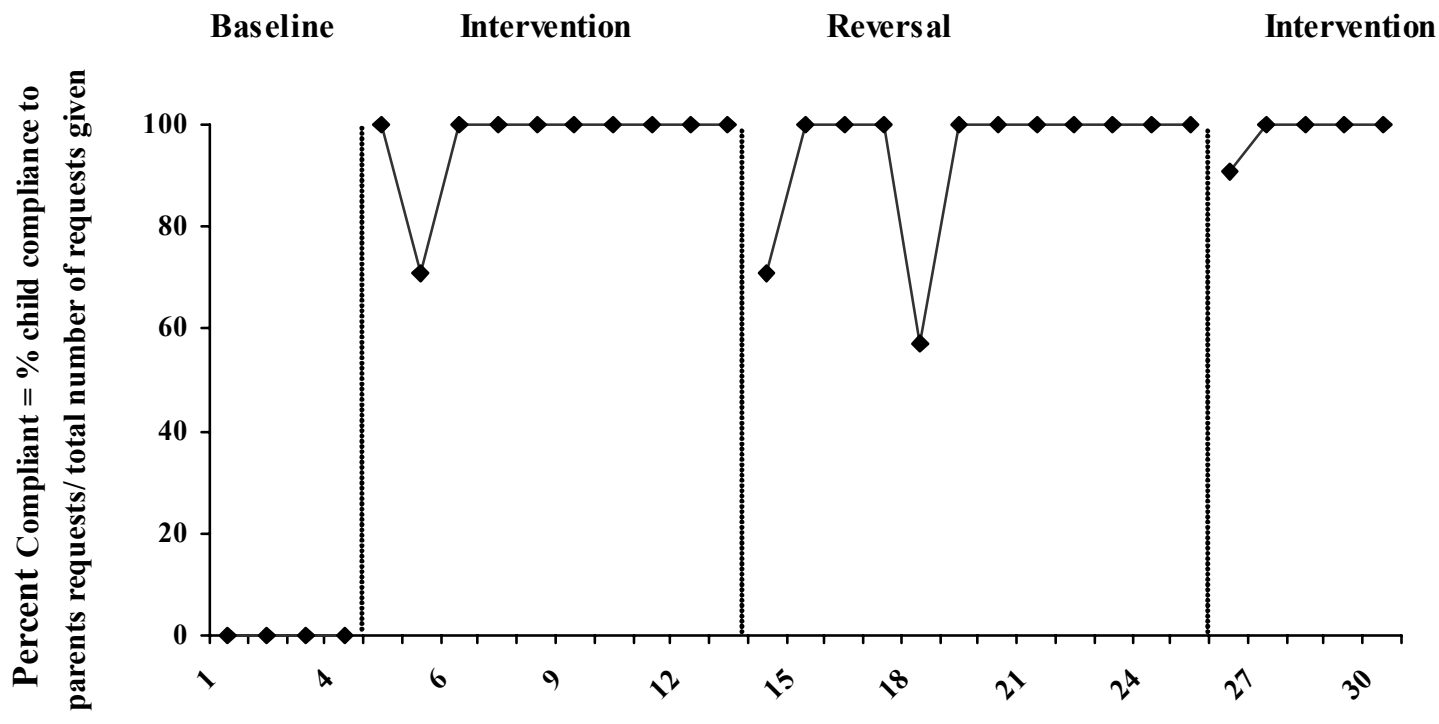

Janis Doe Obs ervations 
Mary

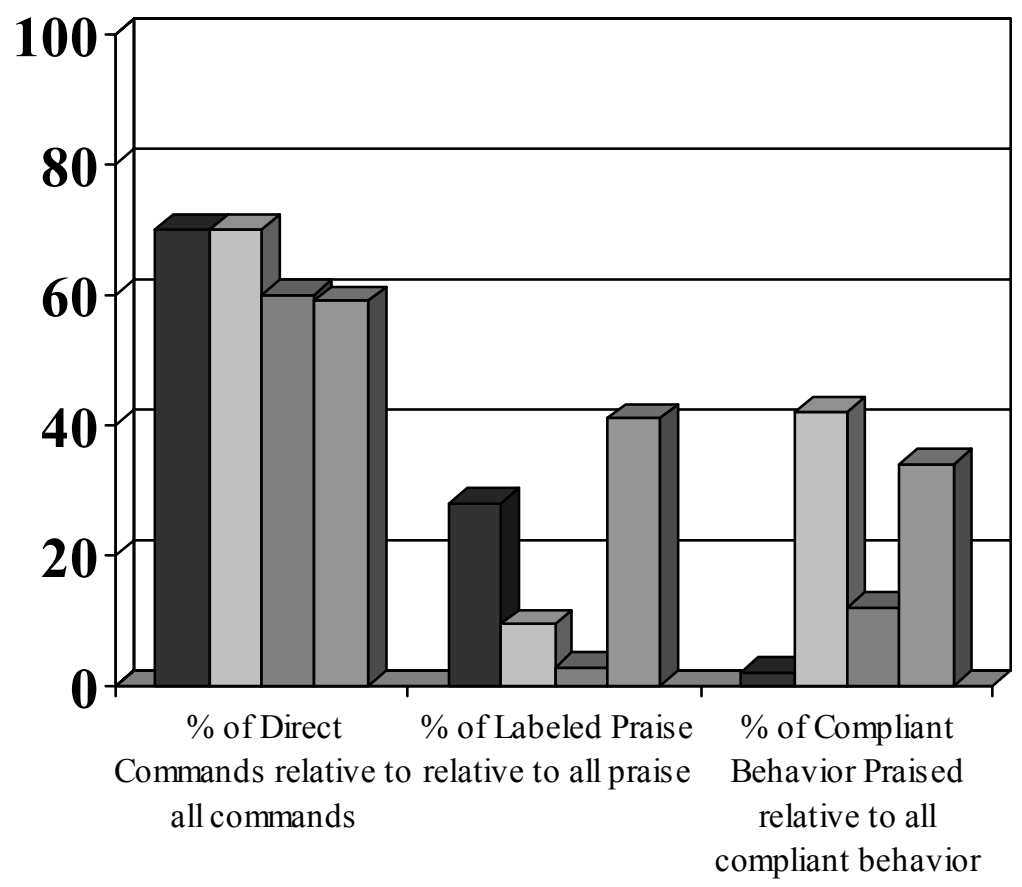

\begin{tabular}{|l|}
\hline$\square$ Baseline \\
$\square$ Intervention \\
$\square$ Reversal \\
$\square$ Intervention \\
\hline
\end{tabular}

Janis

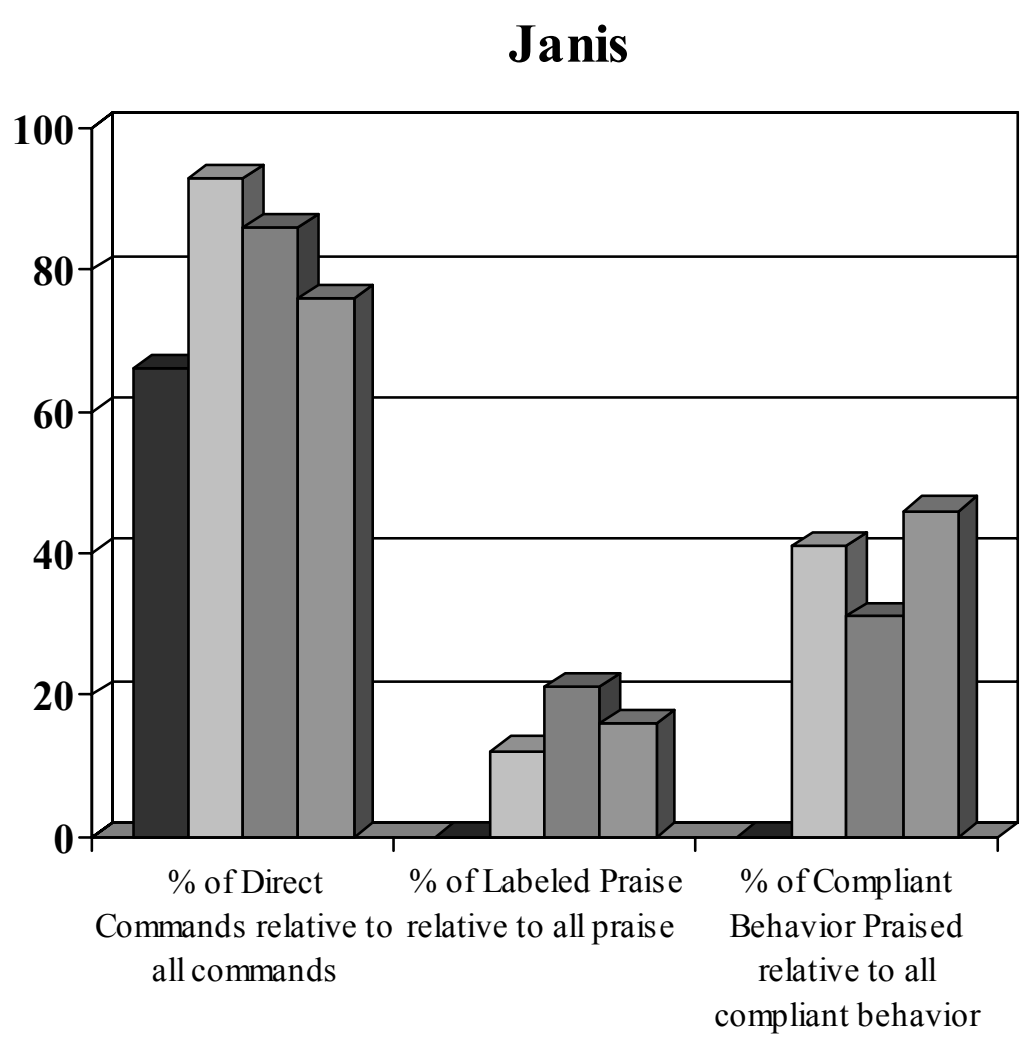

$\square$ Baseline

$\square$ Intervention

Reversal

Intervention 


\section{Mary}

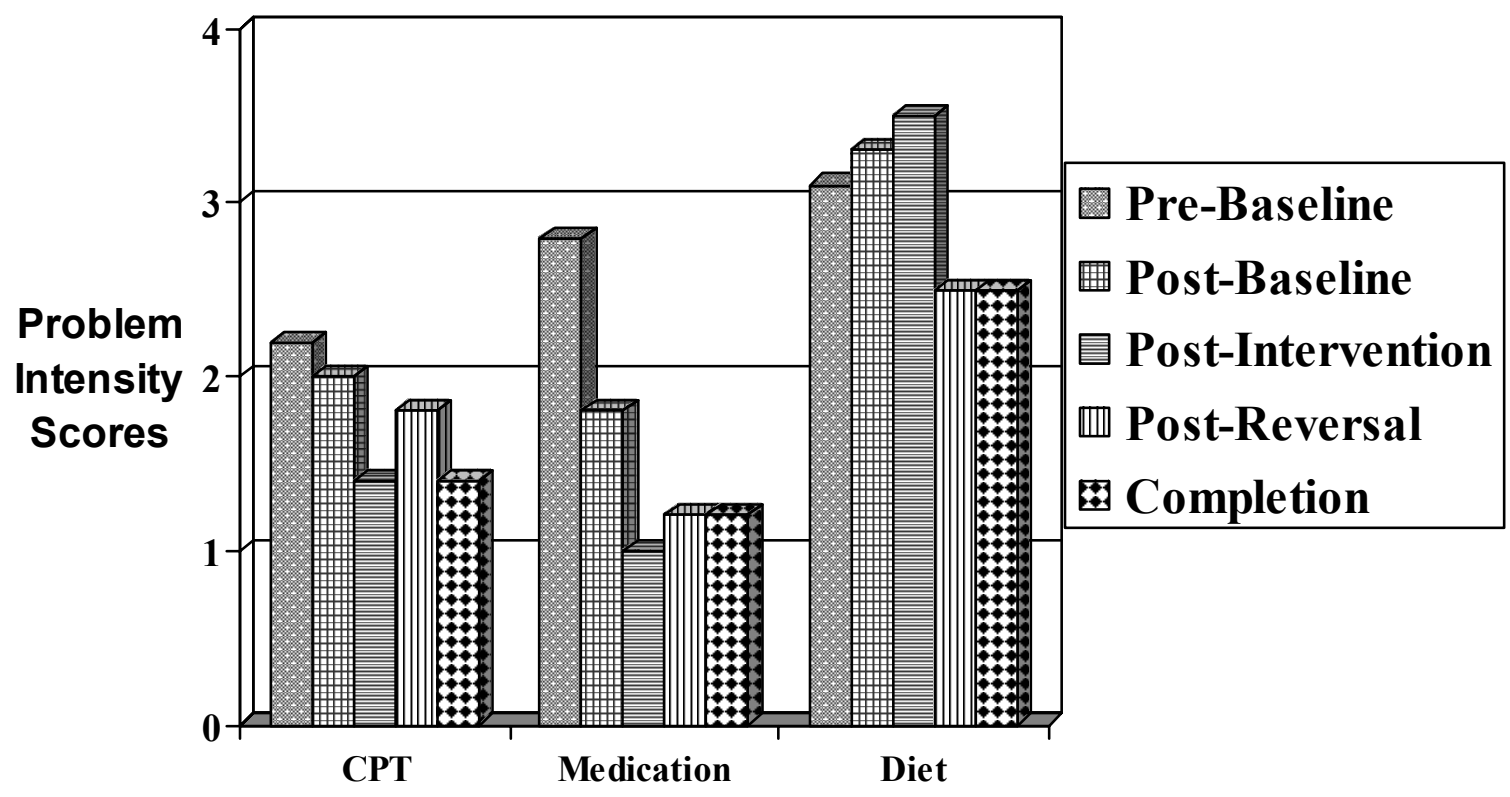

Janis

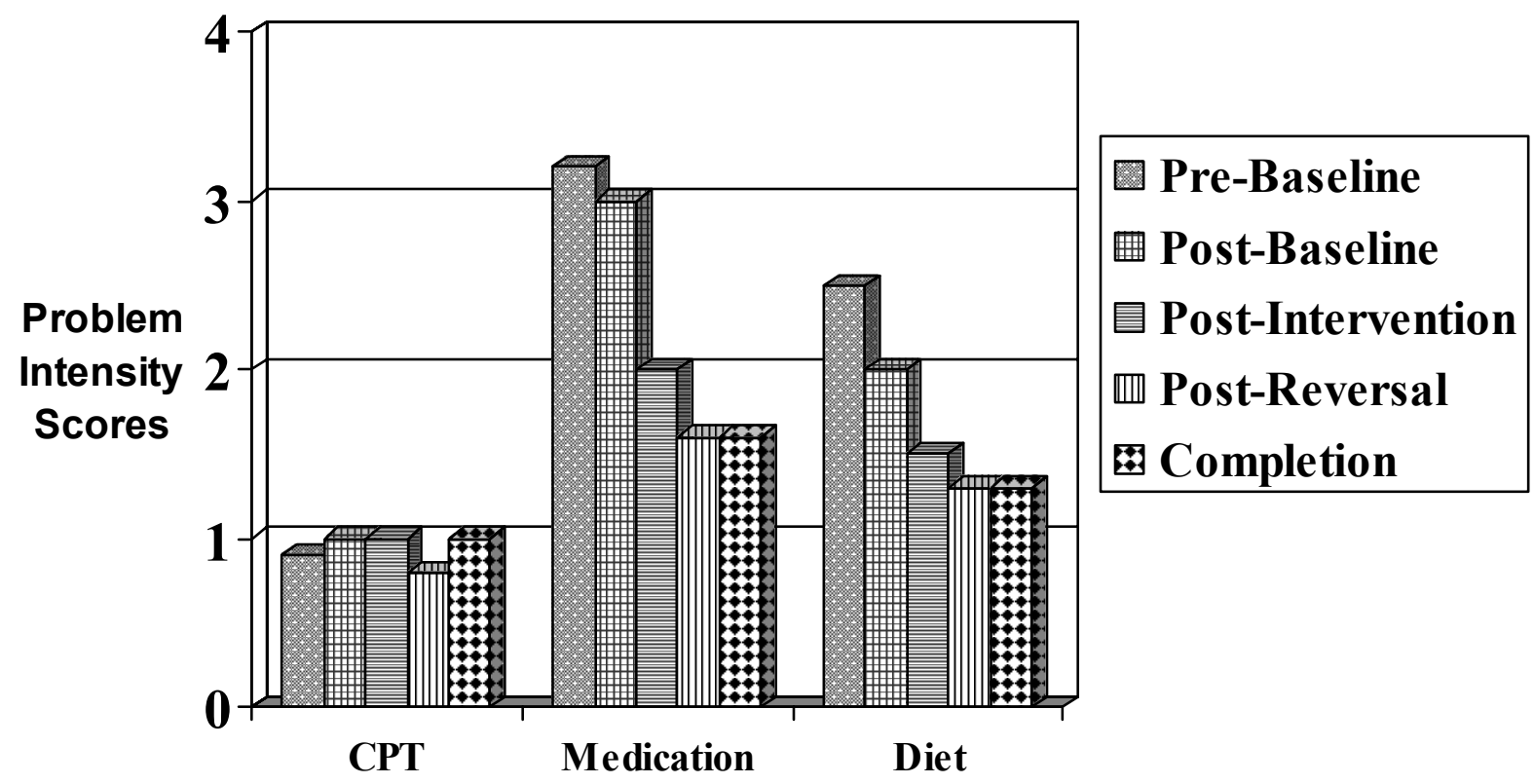


Mary

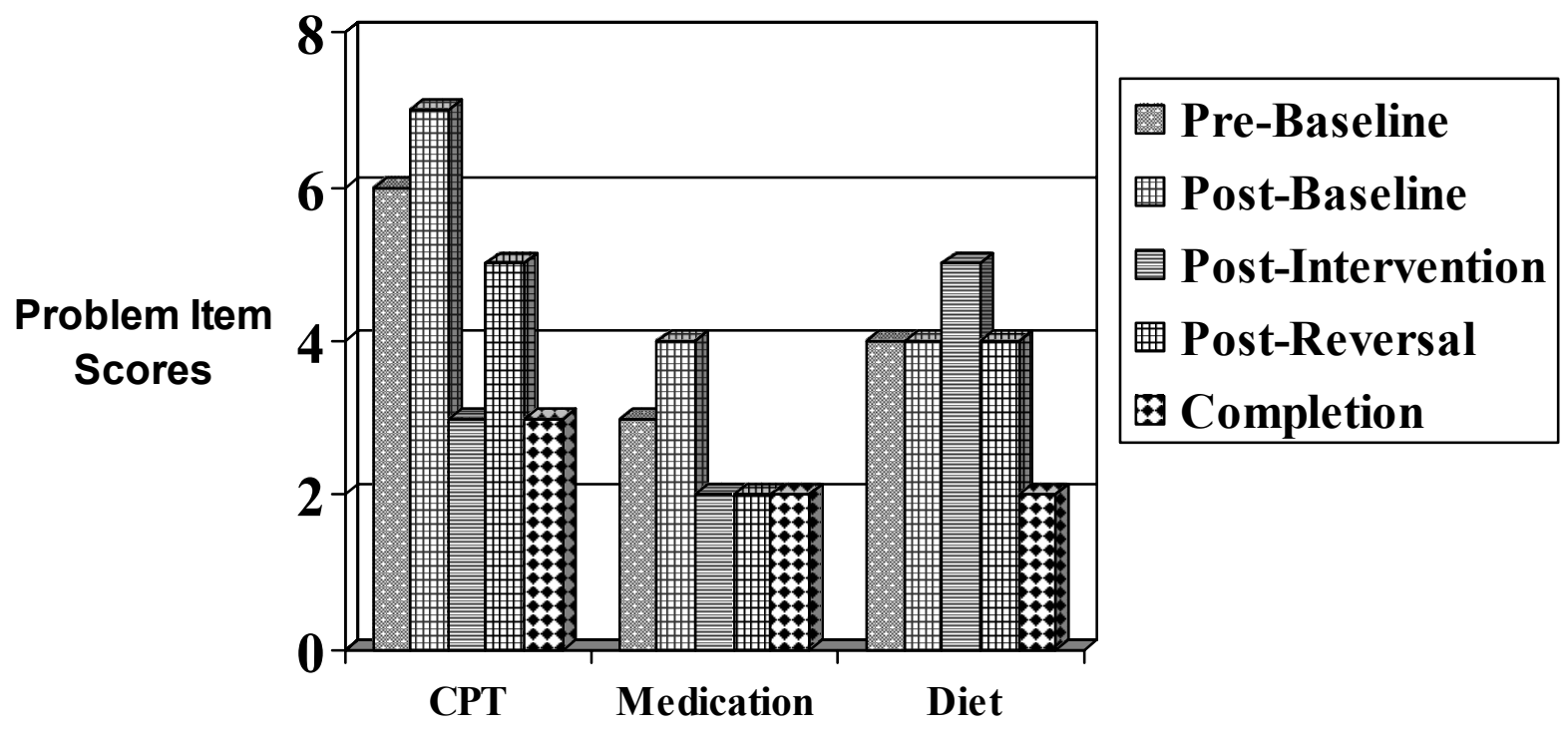

Janis

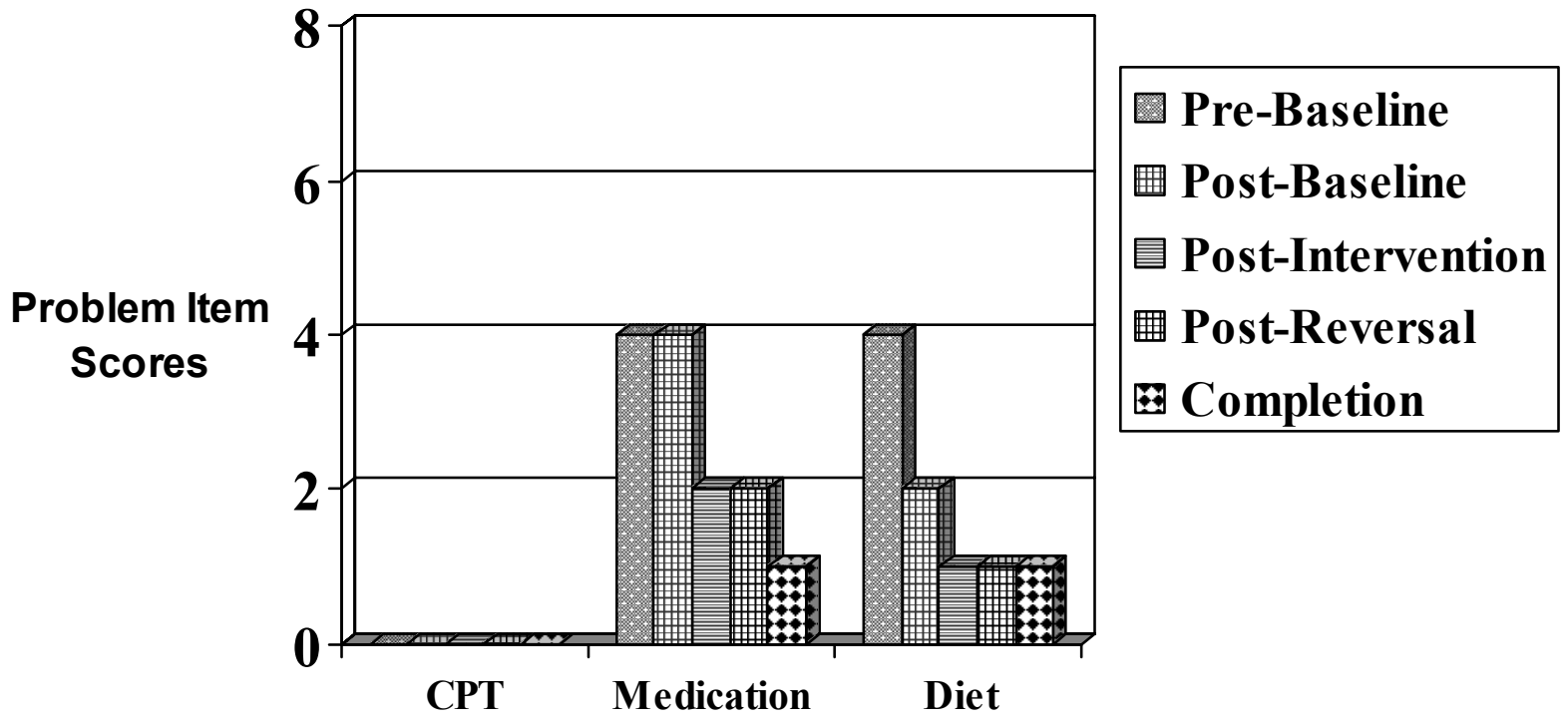

